\title{
NOVAS OCORRÊNCIAS DE FÓSSEIS NAS FORMAÇÕES CORUMBATAÍ E ESTRADA NOVA DO ESTADO DE SÃO PAULO E CONSIDERAÇÕES PRELIMINARES SOBRE SEUS SIGNIFICADOS PALEONTOLÓGICO E BIOESTRATIGRÁFICO
}

\author{
Maria da Saudade A. S. MARANHÃO \\ Setembrino PETRI
}

\section{RESUMO}

O presente trabalho discute ocorrências e posicionamento estratigráfico dos fósseis das formações Corumbataí e Estrada Nova, incluindo espongiários (espículas), ostracodes, microvertebrados (dentes e escamas de paleoniscídeos), estromatólitos, oogônios de carófitas e bivalves que compõem as associações fossilíferas presentes nessas formações. A análise micropaleontológica permitiu: 1) classificar espículas de espongiários como oxeas monoxônidas características da Classe Demospôngia da Ordem Haplosclerida; 2) identificar dezesseis gêneros e vinte e três espécies novas de ostracodes, com base na morfologia externa da carapaça; 3) identificar dez morfotipos de ictiodontes e quatro tipos de escamas de paleoniscídeos; 4) descrever ocorrência de oogônios de carófitas, com os espécimes isolados, pela primeira vez, da rocha matriz. Considera-se a possibilidade das carófitas serem fósseis-índices do topo do Membro Teresina da Formação Estrada Nova, pois apresentam posição estratigráfica restrita e ampla distribuição geográfica. O estudo dos bivalves foi estendido para áreas pouco conhecidas, incluindo as regiões de Santa Cruz das Palmeiras, Tambaú, Porangaba, Angatuba, Guareí, Taguaí e Fartura para mostrar que o zoneamento bioestratigráfico proposto para a região de Rio Claro é válido também para outras áreas de São Paulo. As biozonas apresentam ampla distribuição geográfica como no caso da Zona Pinzonella neotropica-Jacquesia brasiliensis que vai do nordeste ao sudoeste do Estado. As características litológicas, petrográficas e estruturas sedimentares associadas às feições tafonômicas e paleoecológicas dos bioclastos mostraram que a maioria dos fósseis das formações Corumbataí e Estrada Nova não correspondem a deposições in situ, mas foram transportados e redepositados durante sucessivos eventos de tempestades.

\section{ABSTRACT}

Constitution, local and regional ranges and stratigraphic position of fossils of the Corumbataí and Estrada Nova formations sponge spicules, ostracodes, ichthyoliths, coprolites, probable biogenic fragments, charophyte oogonia, stromatolites and bivalves are studied. Micropaleontological analyses allowed to: 1) classify sponge spicules as monaxonid oxeas characteristic of the class Demospongia of the Haploscherida Order; 2) identify, based on the external morphology of the carapace, 16 genera and 23 new species of ostracodes; 3 ) identify 10 morphotypes of ichthyoliths and 4 types of Paleoniscoidei scales; 4) describe, for the first time in Brazil, a charophyte oogonium occurrence in which the paleozoic specimens could be isolated from the rock matrix. The charophyte may eventually prove to be an index fossil as it has so far been registered only at the top of the Teresina Member of the Estrada Nova Formation; 5) identify two distinct groups of probable biogenic fragments. The study of bivalves was extended to the regions of Santa Cruz das Palmeiras, Tambaú, Porangaba, Angatuba, Guareí, Taguaí and Fartura; it is shown that the biostratigraphic zonation proposed for the Rio Claro region can be applied to other areas of the State. The biozones were widely distributed geographically, as for instance the Pinzonella neotropica-Jacquesia brasiliensis Zone, which extends from the northeast to the southwest of São Paulo State. The lithological and petrographic characteristics and the sedimentary structures associated with the taphonomic and paleoecological features of the bioclasts showed that the fossils of the Corumbatai and Estrada Nova formations do not, in general, correspond to in situ depositions, but were transported and redeposited during sucessive storm events. 


\section{INTRODUÇÃO}

Este trabalho apresenta informações sobre fósseis das formações Corumbataí e Estrada Nova pertencentes ao Grupo Passa Dois do Estado de São Paulo, Brasil, de idade neopermiana.

Durante décadas houve tendência em intensificar as pesquisas das ocorrências de bivalves da área de Rio Claro, permanecendo dúvidas quanto ao grau de abrangência dessas biozonas malacofaunísticas e se as mesmas seriam válidas para correlações com outras áreas do Estado.

A partir dos estudos sistemáticos sobre os Chondrichthyes do Membro Taquaral da Formação Irati (RAGONHA, 1978) e Xenacanthodii da Formação Corumbataí (RAGONHA, 1984), houve avanço também nos estudos das ictiofaunas do Grupo Passa Dois.

Entretanto, os paleoniscídeos mesmo sobrepujando quantitativamente os outros grupos de peixes, continuavam pouco conhecidos, sem descrições dos morfotipos encontrados nas formações Estrada Nova e Corumbataí do Estado .

DUNKLE \& SCHAEFER (1956) foram precursores no estudo desse grupo de peixes, descrevendo um exemplar completo, o qual foi descoberto na rodovia Conchas-Botucatu (SP). A segunda ocorrência de exemplares completos foi de SILVA-SANTOS (1991) que noticiou quatro exemplares coletados em Angatuba (SP). Os demais registros constam de citações sobre a presença de elementos exoesqueletais isolados, sem descrições dos morfotipos encontrados. A principal informação sobre essas peças é uma estampa apresentada por WÜRDIG-MACIEL (1975) que ilustrou ictiodontes e escamas da Formação Estada Nova (na nossa concepção Corumbataí) da região de Piracicaba (SP), sem discutir as características morfológicas dos tipos documentados.

A análise paleontológica envolveu também as espículas de espongiários já mencionadas por WASHBURNE (1930). A distribuição desses microrrestos foi avaliada por FULFARO (1970) que recuperou espículas no intervalo compreendido entre o topo do Grupo Tubarão ao topo do Grupo Passa Dois, mas esse material não foi documentado.

Nesse mesmo contexto, inseriam-se os ostracodes, com apenas uma ocorrência estudada por SOHN \& ROCHA-CAMPOS (1990), nas proximidades de Conchas (SP), em sedimentos da Formação Estrada Nova.

Assim, o objetivo deste trabalho foi ampliar o conhecimento sobre a distribuição dos bivalves em áreas pouco conhecidas no Estado, concomitantemente documentando os microfósseis e microrrestos coletados em vários níveis das seções examinadas, de modo a avaliar o conteúdo fossilífero das formações Estrada Nova e Corumbataí em diferentes pontos do Estado.

Entretanto, por tratar-se de assunto muito extenso, serão apresentadas discussões resumidas sobre essas ocorrências fossilíferas, as descrições detalhadas e documentação fotográfica completa sobre cada grupo serão objeto de diversos trabalhos específicos, em elaboração.

\section{CONSIDERAÇÕES LITOESTRATIGRÁFICAS}

Desde a sua introdução na literatura, os termos Estrada Nova e Corumbataí vêm sendo aplicados no Estado de São Paulo, para a seqüência superior do Grupo Passa Dois, sem critérios seguros devido à:

1) dificuldade para a perfeita caracterização das unidades estratigráficas e suas inter-relações espaciais no Estado;

2) dificuldade de correlação entre a Formação Estrada Nova presente nos estados do Paraná e Santa Catarina, subdividida em membros e aquela aflorante em São Paulo, com características litofaciológicas distintas.

No Estado de São Paulo, a indivisibilidade da Formação Estrada Nova foi mantida por FULFARO (1970), LANDIM (1970) e ZAINE (1980); menciona-se, contudo, a ocorrência de fácies evocativas dos membros estabelecidos por GORDON Jr. (1947).

Para alguns autores, entretanto, a subdivisão da Formação Estrada Nova aplicável a Santa Catarina e Paraná pode também ser reconhecida até a área centro-sul de São Paulo.

Neste contexto, LELLIS (1970) caracterizou, como típica fácies Serra Alta, a litologia encontrada na região de Pereiras-Cesário LangeBofete (SP), onde a seqüência é constituída por siltito maciço, de cor cinza escura, com fratura conchoidal, associado com concreções elípticas e níveis de calcário com espessuras variáveis, desde poucos centímetros até $30 \mathrm{~cm}$.

VIEIRA (1973) denominou Grupo Estrada Nova ao conjunto das formações Irati, Serra Alta e Teresina. A Formação Serra Alta, segundo esse autor (op. cit.), estende-se "do sul até próximo à estrada Itapetininga-Guareí, onde se confunde com a base da Formação Teresina (Corumbataí), para voltar a reaparecer em sua litologia típica nas proximidades da Rodovia Castello Branco". Com relação à Formação Teresina, chamou a atenção para a variação nas tonalidades dos sedimentos, cinzas ou verdes no Paraná, que adquirem coloração avermelhada, no Estado de São Paulo, onde passa a ser denominada de Corumbataí. 


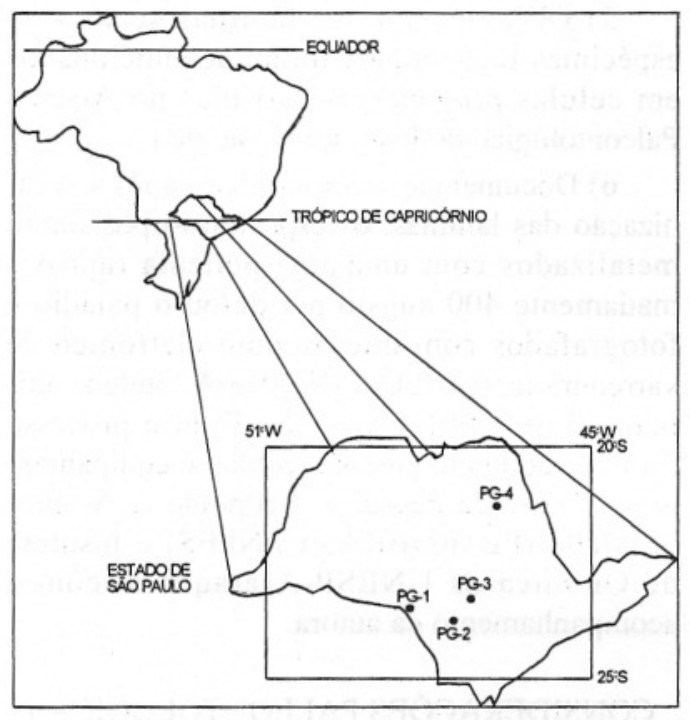

FIGURA 1 - Mapa de localização dos perfis geológicos. PG 1: Pedreira Pau Preto (Folha 1:50.000 de Sarutaiá); PG 2: Estrada de Angatuba (Folha 1:50.000 de Aracaçu); PG 3: km 161,5 da Rod. Castello Branco (Folha 1:50.000 de Conchas); PG 4: Fazenda Itaoca (Folha 1:50.000 de Santa Rita do Passa Quatro).

No mapa geológico do Estado de São Paulo publicado em 1981, pelo Instituto de Pesquisas Tecnológicas, o termo Estrada Nova foi aplicado para a seqüência, subdividida em membros Serra Alta e Teresina, enquanto Corumbataí foi empregado para a unidade litoestratigráfica indivisa (ALMEIDA \& MELO, 1981).

MELLO E SOUSA (1985) adotou essa mesma idéia, considerando as formações Estrada Nova e Corumbataí estratigraficamente correlatas. Na sua opinião, a Formação Estrada Nova, subdividida nos membros Serra Alta (inferior) e Teresina (superior), aflora na porção sudoeste do Estado de São Paulo, desde a divisa do Paraná até o Rio Tietê, nas proximidades da cidade de Piracicaba (SP). A partir desse ponto, em direção ao flanco nordeste do Estado, por recorrência das litologias seria preferível aplicar à seqüência o termo Corumbataí.

A nomenclatura adotada, no presente trabalho, concorda com essa conceituação.

\section{METODOLOGIA}

Trabalhos de Campo

Foram levantadas 21 seções estratigráficas (in MARANHÃO, 1995) sendo que as correspondentes à Formação Corumbataí localizam-se no norte do Estado, na área de Rio Claro, e mais ao nordeste, nas regiões de Santa Cruz das Palmeiras e Tambaú.

Os afloramentos da Formação Estrada Nova compreendem as ocorrências situadas no centro-sul, em Angatuba, Porangaba e Guareí, e na área sudoeste, nas regiões de Taguaí e Fartura. Para este trabalho foram escolhidos quatro perfis localizados no Estado, conforme a FIGURA 1, para orientação do leitor quanto ao posicionamento dos níveis fossilíferos. $\mathrm{Na}$ FIGURA 2 são apresentadas as legendas dos perfis da Formação Estrada Nova (FIGURAS 3, 4 e 5) e da Formação Corumbataí (FIGURA 6).

\section{Análises Laboratoriais}

A metodologia adotada para o tratamento de amostra seguiu os procedimentos recomendados pelos laboratórios da PETROBRÁS, adaptados ao material em questão que consiste de:

1) Pesagem de amostras - a quantidade estabelecida foi de $500 \mathrm{~g}$ de material previamente desagregado, para facilitar a reação química.

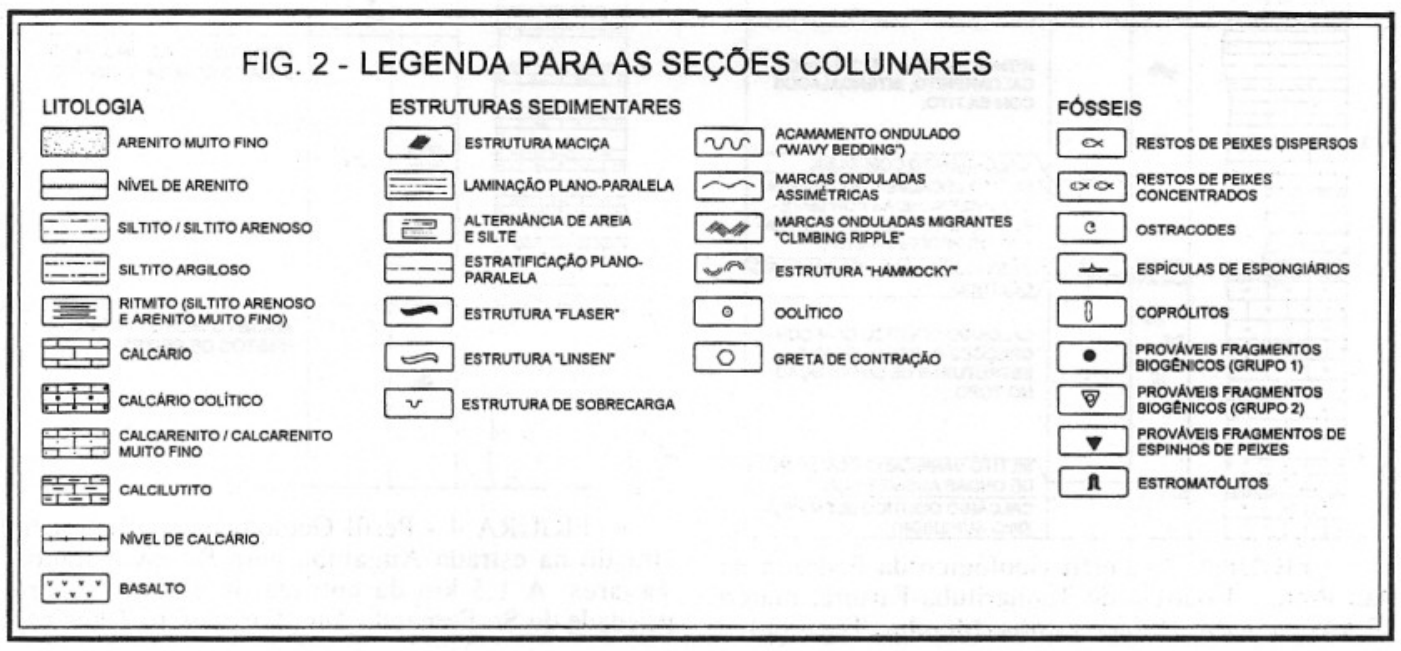


2) Adição de água oxigenada a 130 volumes - as amostras foram submetidas ao ataque por água oxigenada visando sua desagregação e oxidação da matéria orgânica. $\mathrm{O}$ volume adicionado de água oxigenada variou de $100 \mathrm{a} 300 \mathrm{ml}$, sendo o tempo de reação estabelecido em aproximadamente 24 horas.

3) Lavagem e secagem das amostras - as amostras foram separadas em peneiras de malhas $0,71 \mathrm{~mm}, 0,50 \mathrm{~mm}, 0,250 \mathrm{~mm}, 0,177 \mathrm{~mm}$, $0,125 \mathrm{~mm}, 0,062 \mathrm{~mm}$ e $0,037 \mathrm{~mm}$, sob água corrente e colocadas para secar à temperatura de $60^{\circ} \mathrm{C}$, na estufa.

4) Triagem - as frações granulométricas foram pesadas e acondicionadas em frascos devidamente identificados, procedendo-se à separação dos microfósseis e microrrestos.

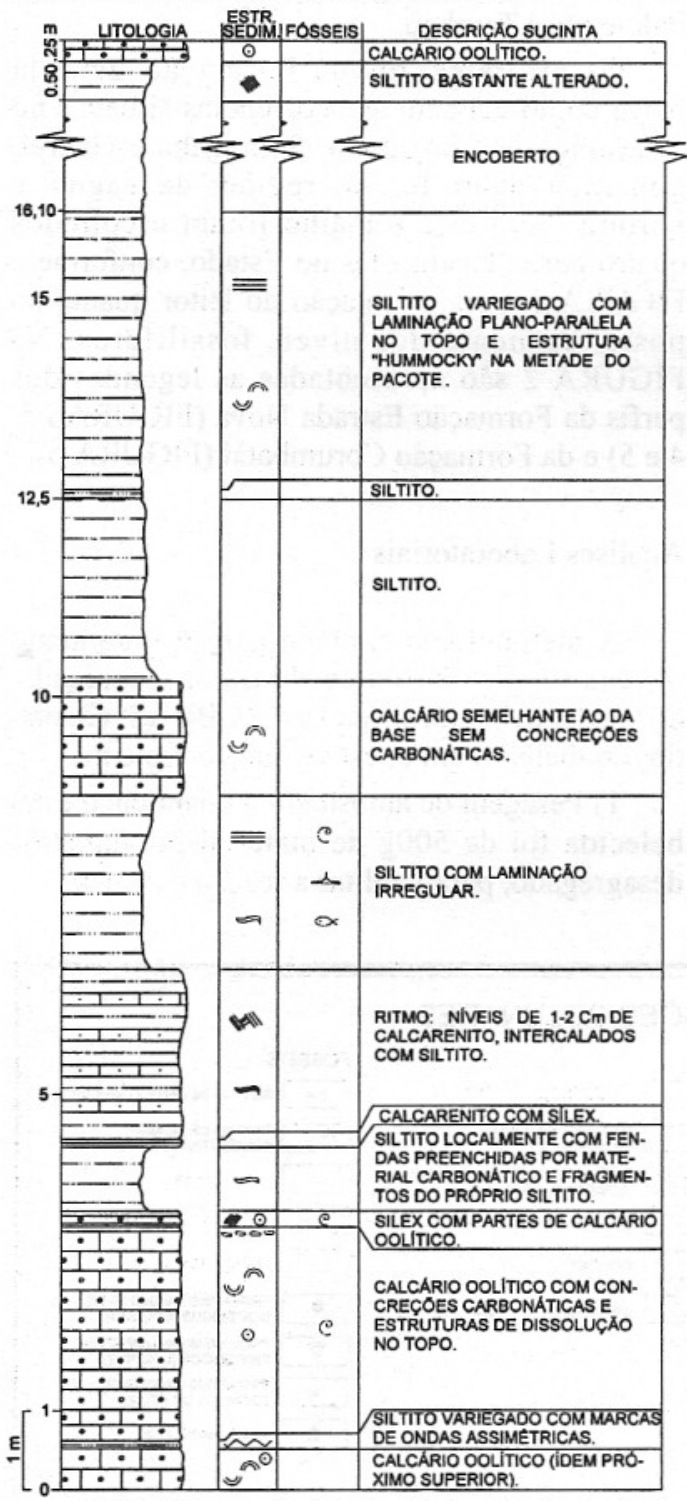

FIGURA 3 - Perfil Geológico da Pedreira de Pau Preto - Rodovia de Taquarituba-Fartura, marco 12,4 km a partir de Taquarituba (Membro Teresina).
5) Organização das lâminas secas - os espécimes recuperados foram acondicionados em células plummer, arquivadas no Acervo Paleontológico do Instituto Geológico.

6) Documentação fotográfica - após a organização das lâminas, os espécimes-tipos foram metalizados com uma fina película (aproximadamente 400 angstrons) de ouro paládio e fotografados com microscópio eletrônico de varredura marca JEOL JXA-840A, onde se utilizou câmera PENTAX-MX. Todo o processo foi realizado pelo pessoal técnico e equipamento do Centro de Pesquisas Leopoldo A. Miguez de Mello (PETROBRÁS/CENPES) e Instituto de Química da UNESP-Araraquara, com o acompanhamento da autora.

\section{CONSIDERAÇÕES PALEONTOLÓGICAS}

A associação fossilífera presente nas formações Corumbataí e Estrada Nova compreende espongiários (espículas), ostracodes, ictiofósseis, coprólitos, prováveis fragmentos biogênicos, oogônios de carófitas, bivalves e estromatólitos. Os critérios utilizados para as

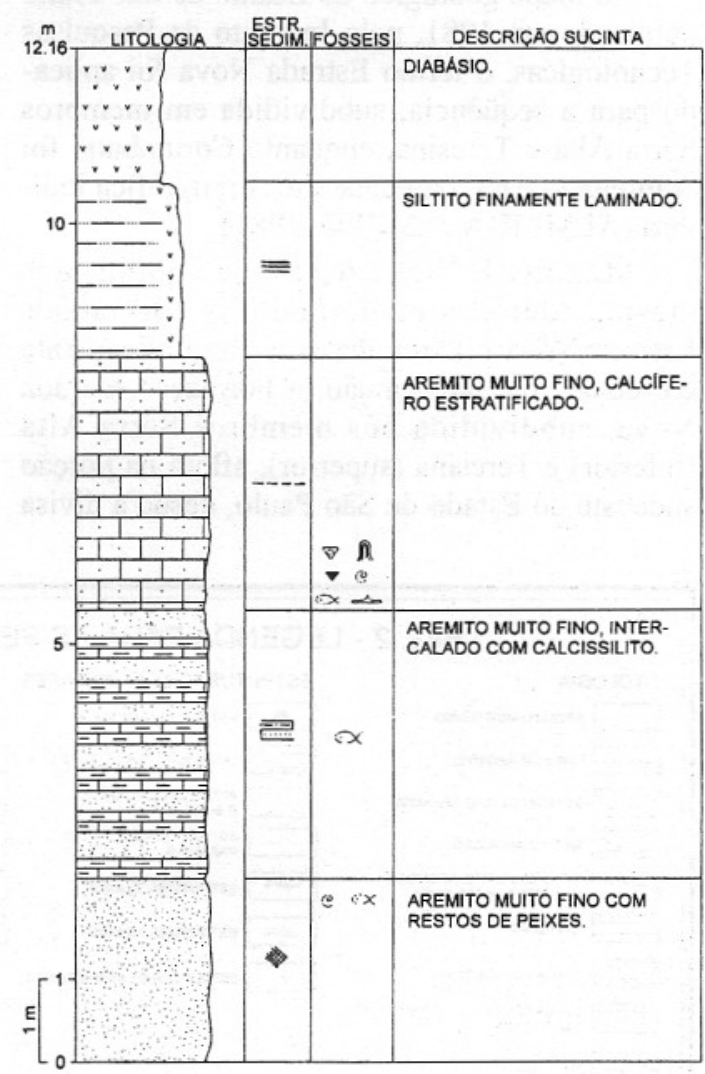

FIGURA 4 - Perfil Geológico do afloramento situado na estrada Angatuba para Rodovia Raposo Tavares. A $1,5 \mathrm{~km}$ da entrada da cidade, na propriedade do Sr. Fernando Turelli (Membro Teresina). 
descrições e classificações dos vários grupos serão discriminados a seguir:

\section{Espículas de Espongiários}

As espículas descritas neste trabalho encontram-se arquivadas na Fundação Zoobotânica do Rio Grande do Sul.

Na ESTAMPA 1 estão ilustradas algumas espículas isoladas classificadas como espículas oxeas monaxônidas características da Classe Demospôngia, da Ordem Haplosclerida (BERGQVIST, 1978). Não foram encontrados vestígios de sua organização nos esqueletos das esponjas.

Associados às espículas, foram encontrados microrrestos identificados como possíveis ossículos (elementos calcíticos do esqueleto) de ofiuróides.

\section{Ostracodes}

Os ostracodes descritos neste trabalho encontram-se arquivados temporariamente no Acervo do CENPES - PETROBRÁS.

$\mathrm{Na}$ ausência de caracteres morfológicos como: charneira, impressões musculares cen-

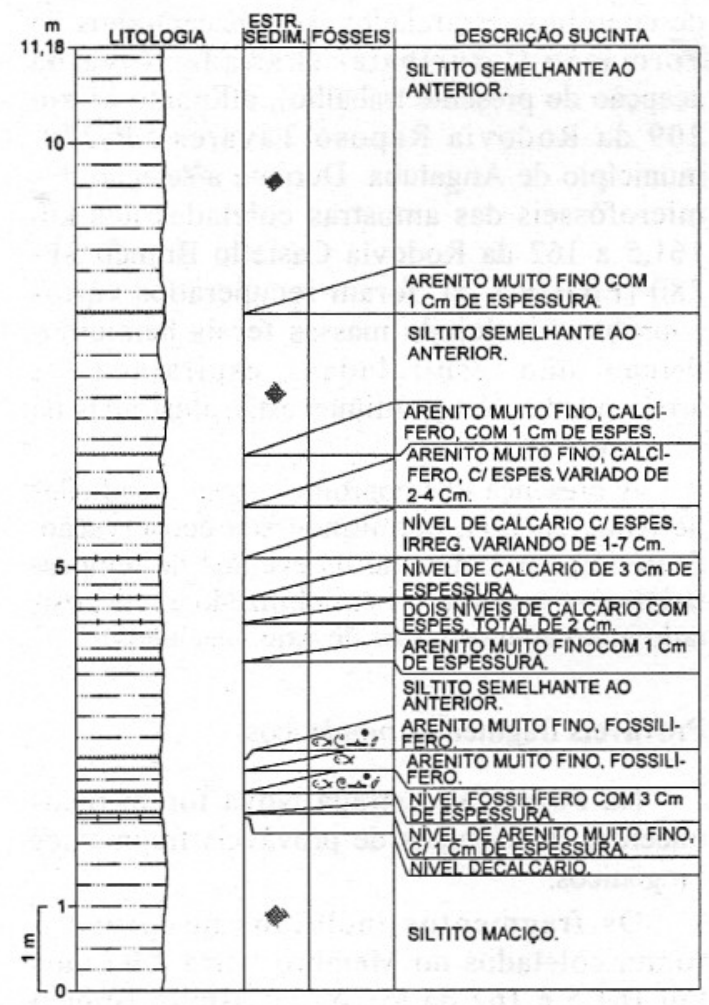

FIGURA 5 - Perfil Geológico do afloramento situado no km 161,5 da Rodovia Castello Branco (Membro Serra Alta). trais, tipo, número e posição dos porocanais e vestíbulo, adotou-se a classificação artificial, baseada em características externas das valvas direita e esquerda, relação de recobrimento das valvas e contorno da carapaça em vista dorsal, que permitiu a identificação de 23 morfoespécies distribuídas por 16 morfogêneros. $O$ gênero 1 espécie 1 definido nesse trabalho está ilustrado na ESTAMPA 2.

No trabalho de SOHN \& ROCHA-CAMPOS (1990) sobre ostracodes da Formação Corumbataí, os espécimes descritos foram atribuídos com dúvidas aos gêneros Cypridopsis, Candona e Darwinula, além de três espécies assinaladas a um gênero desconhecido; as descrições apresentadas, entretanto, não trazem detalhes sobre as características das duas valvas e relações de recobrimento, impossibilitando comparar os morfotipos aqui descritos com o material estudado por esses autores (op. cit.). Apenas o gênero 2 espécie 1 foi relacionado ao gênero desconhecido espécie 1 figurado por SOHN \& ROCHA-CAMPOS (op. cit.) na figura 6.13. Por outro lado, o gênero 4 espécie 1 apresenta relações de contorno com Candona sp. figurada por SOHN \& ROCHA-CAMPOS (op. cit.). Variações são observadas, entretanto, quanto ao contorno da carapaça em vista dorsal. A dificuldade de identificação das relações de recobrimento das carapaças descritas impede caracterizar, sob esse aspecto, possível identidade entre essas formas. Entretanto, detalhes das margens livres indicam a provável sobreposição da valva esquerda sobre a direita ao longo das mesmas.

\section{Ictiofósseis}

Os ictiodontes e escamas descritos neste trabalho encontram-se depositados no Acervo Paleontológico do Instituto Geológico, sob a sigla MP-IG-MV-1 a MP-IG-MV-131 (MP = Museu Paleontologia, IG = Instituto Geológico e $\mathrm{MV}=$ microvertebrados).

A maioria dos morfotipos documentados foram recuperados nas amostras coletadas nos km 161,5 a 162 Rodovia Castello Branco, SP280 (FIGURA 5), que reúne os microvertebrados mais diversificados e melhor preservados. Inicialmente, os ictiodontes foram identificados através de microscopia óptica, em tipos designados pelas letras A, B, C, D, F e G, conforme classificação proposta por WÜRDIG-MACIEL (1975). Para observação do espécime completo e da micrornamentação do capuz apical e da fuste dentária foram obtidas fotomicrografias ao microscópio eletrônico de varredura, MEV (conforme procedimento descrito em RICHTER et 
al., 1985). Os aumentos utilizados para os exemplares variaram de 25 a 100 vezes, enquanto para o capuz e a fuste esse aumento foi de 1000 vezes.

Com base na ornamentação da fuste e capuz apical, ao MEV, foram descritos novos morfotipos designados de Ictiodonte L, Ictiodonte $\mathrm{M}$, Ictiodonte $\mathrm{N}$ e Ictiodonte $\mathrm{O}$. Foram também identificados subtipos dos ictiodontes $\mathrm{A}, \mathrm{C}$ e $\mathrm{F}$, designados pela mesma

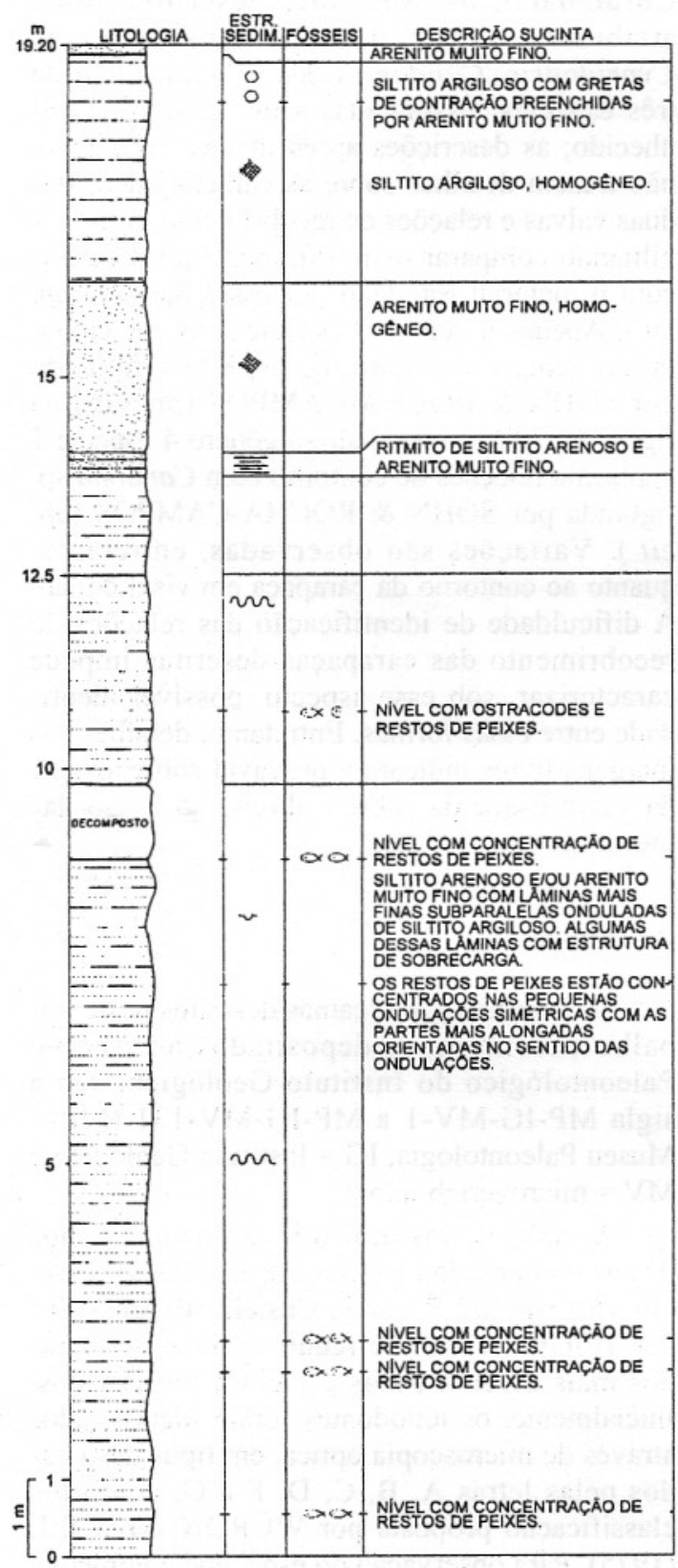

FIGURA 6 - Perfil Geológico do afloramento situado em frente à sede da Fazenda Itaoca, distante 4 km da estrada Porto Ferreira - Tambaú, a $11 \mathrm{~km}$ da cidade de Santa Cruz da Estrela (Formação Corumbataí). letra do morfotipo, acompanhada de um número (o ictiodonte F-1 está ilustrado na ESTAMPA 4).

Dentre os vários tipos de ornamentação observados ao MEV, o mais freqüente consiste de tubérculos fusiformes, distribuídos longitudinalmente por toda a superfície da fuste dentária, estendendo-se às faces laterais. O capuz apical apresenta-se liso ou com sulcos e cristas que, pela disposição, lembram o padrão fusiforme observado na fuste (ESTAMPAS 3 e 4).

Para a identificação das escamas adotou-se a classificação morfológica proposta por RICHTER et al. (1985), considerando-se as seguintes feições: forma geral da escama, ornamentação superficial ao microscópio óptico, processos articulares, características das margens das escamas e padrão de ornamentação observado ao MEV.

Assim, identificaram-se escamas dos tipos P-1, P-2, P-3 (esta última ilustrada na ESTAMPA 5) e C-1?, que guardam estreita relação com os morfotipos descritos e figurados por RICHTER (1981) e RICHTER et al. (1985).

\section{Coprólitos}

RAGONHA (1987) registrou a presença de coprólitos espiralados de xenacantódios na Formação Corumbataí (Estrada Nova na acepção do presente trabalho), aflorante no km 209 da Rodovia Raposo Tavares SP-270, município de Angatuba. Durante a seleção dos microfósseis das amostras coletadas nos km 161,5 a 162 da Rodovia Castello Branco SP280 (FIGURA 5), foram recuperados vários coprólitos, incluindo massas fecais hemicilíndricas não espiraladas, espiraladas e arredondadas (estas últimas estão ilustradas na ESTAMPA 6).

A presença dos coprólitos atesta condições de baixa energia, permitindo sua conservação. Posteriormente, durante os eventos de tempestades, esse material foi remobilizado e redepositado junto com os restos de paleoniscídeos.

\section{Prováveis fragmentos biogênicos}

$\mathrm{Na}$ Formação Estrada Nova foram reconhecidos dois grupos de prováveis fragmentos biogênicos.

Os fragmentos incluídos no Grupo 1 foram coletados no Membro Serra Alta, nos km 161,5 e 162 da Rodovia Castello Branco (FIGURA 5), distinguindo-se, nesse caso, fragmentos de formas triangulares e semicirculares, translúcidos, moderadamente infla- 
dos e com extremidades proeminentes (os primeiros estão ilustrados na ESTAMPA 7).

Nota-se nas fotomicrografias ao MEV que os dois tipos de exemplares apresentam superficies externas com pontuações semelhantes às encontradas nas escamas (P-1) e estão associados aos ictiodontes e escamas (do tipo P-1 e P3) de paleoniscídeos, o que sugere tratar-se de microrrestos desse grupo.

Os fragmentos do Grupo 2 foram recuperados no afloramento do Membro Teresina, situado na estrada de Angatuba para a Rodovia Raposo Tavares, a 1,5km dessa cidade (FIGURA 4), distinguindo-se fragmentos silicificados com fina ornamentação de estrias subparalelas ao comprimento (ESTAMPA 8), associados com prováveis fragmentos de espinhos de peixes.
Morfotipos semelhantes aos fragmentos silicificados foram também encontrados em Rio Claro, em amostras da Formação Corumbataí, coletadas no afloramento situado na estrada vicinal para a Fazenda Santana de Urucaia, $1 \mathrm{~km}$ do Ribeirão Batalha, $6 \mathrm{~km}$ do trevo de Rio Claro, pela Rodovia Wilson Sinardi, no sentido Ipeúna (MARANHÃO, 1995, fig. 19).

\section{Oogônios de Carófitas}

A recuperação, pela primeira vez, de espécimes silicificados de oogônios isolados da matriz, no afloramento às margens da Represa Xavantes (ESTAMPA 9), possibilitou complementar a descrição de Leonardosia langei (MARANHÃO et al., em elaboração) proposta

\section{ESTAMPA 1}

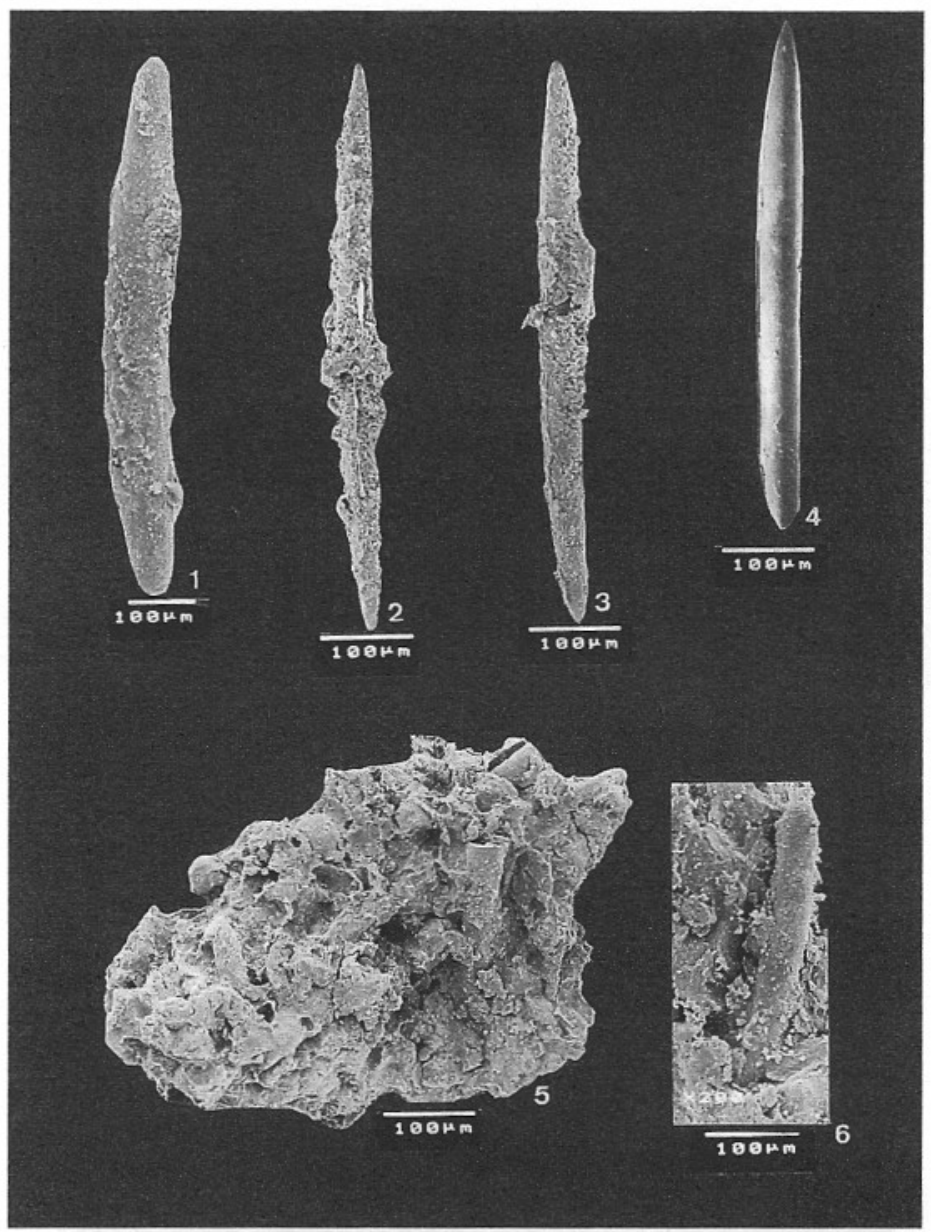

\section{ESPÍCULAS DE ESPONGIÁRIOS}

Fig. 1 Megasclera oxea (X200); Fig. 2 Megasclera oxea (X200); Fig. 3 Megasclera oxea (X200); Fig. 4 Megasclera oxea (X150); Fig. 5 Rocha com restos de espículas (X100); Fig. 6 Detalhe da figura 5 (X200); Procedência: afloramento situado na estrada de Angatuba, a 1,5km da entrada para a cidade, na propriedade do Sr. Fernando Turelli. 
por SOMMER (1954), que se baseou em contramoldes.

Na Formação Estrada Nova, este vegetal parece ter distribuição horizontal ampla, porém restrita ao topo do Membro Teresina, o que reforça sua utilização eventual como fóssilíndice.

\section{Bivalves}

A descrição de seis novas espécies e de dois novos gêneros identificados durante a pesquisa, bem como a complementação da diagnose de Naiadopsis lamellosus Mendes será objeto de trabalho específico desenvolvido por MARANHÃO \& MEZZALIRA (em elaboração).
Estromatólitos

Em nova ocorrência em Taguaí (SP), MARANHÃO, 1995, fig. 30B, foram identificados preliminarmente filmes microbianos, crostas microbianas ou estromatólitos estratiformes e estromatólitos dômicos ou nodulares constituídos por domos múltiplos, encontrados em calcarenito parcialmente silicificado associado com calcissiltito com estratificação cruzada e ondulada.

\section{PALINOLOGIA}

Num total de três amostras coletadas, foram recuperados palinomorfos em somente duas, procedentes dos seguintes locais:

\section{ESTAMPA 2}

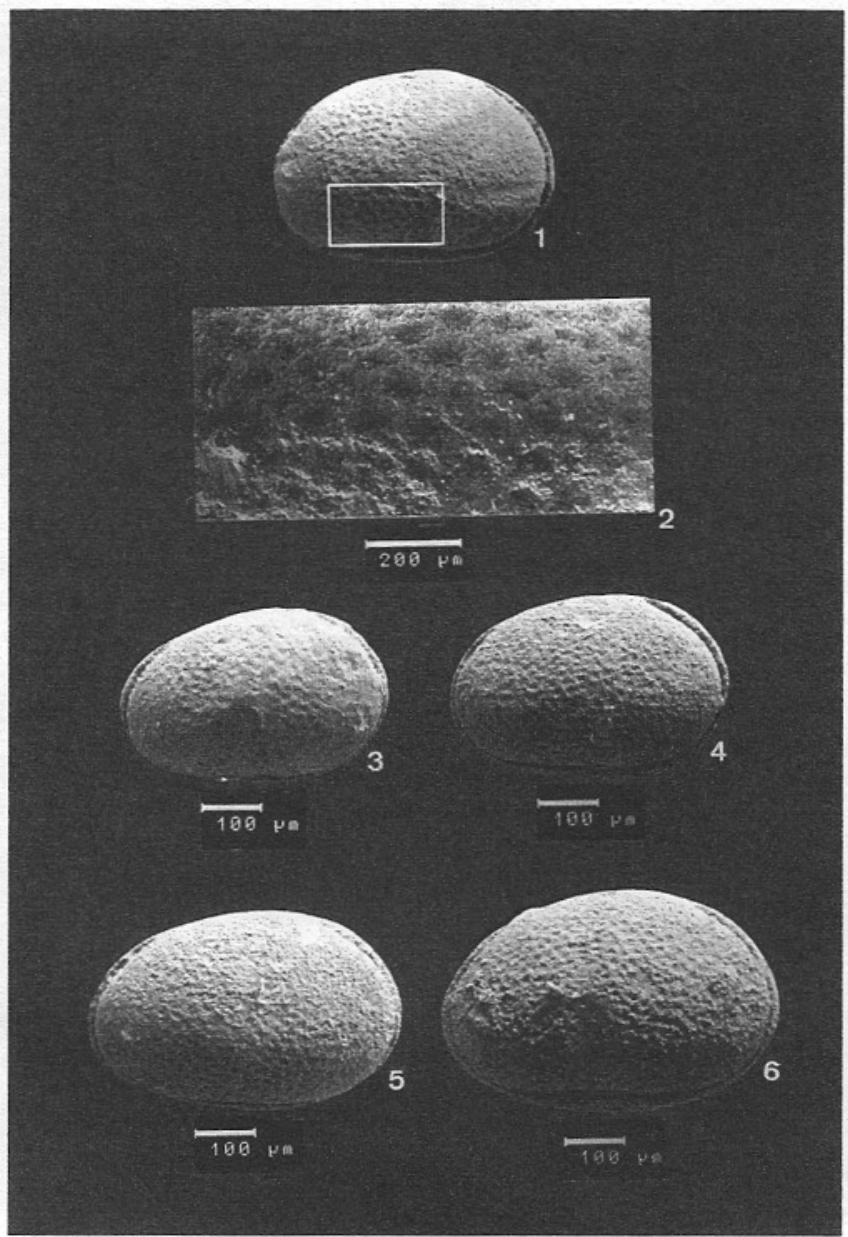

OSTRACODES

Fig. 1 Gênero 1 espécie 1 - Parátipo. Valva direita (X96); Fig. 2 Detalhe da ornamentação da valva direita (X192); Fig. 3 a 6 Série ontogenética; Fig. 3 Valva direita (X120); Fig. 4 Valva esquerda (X120); Fig. 5 Valva direita (X120); Fig. 6 Valva esquerda (X120); Procedência: Pedreira de Pau Preto (município de Taguaí)

- Rodovia Taquarituba-Fartura, SP-249, marco 12,4km a partir de Taquarituba. 
- Amostra 1 (Membro Serra Alta): km 162 da Rodovia Castello Branco, SP-280;

-Amostra 2 (Membro Serra Alta): km 161,5 Rodovia Castello Branco, SP-280.

Estas amostras foram submetidas a tratamento palinológico no Setor de Bioestratigrafia e Paleoecologia do CENPES (PETROBRÁS), sendo os estudos realizados pelo Dr. Rodolfo Dino e pelo Geólogo Mitsuru Arai.

A amostra 1 apresentou raros palinomorfos severamente carbonificados e/ou oxidados, o que impediu qualquer identificação taxonômica. A amostra 2 forneceu os seguintes táxons:

Alisporites aff. nuthallensis, Corisaccites vanus, Limitisporites sp., Lueckisporites virkkiae e Vittatina? sp.
Além destes, foram observados alguns grãos de pólen dissacado indeterminado (ARAI \& DINO, 1995).

De acordo com ARAI \& DINO (op. cit.) "a associação polínica da amostra 2 relaciona-se ao "Intervalo L" de DAEMON \& QUADROS (1970) e à Zona Lueckisporites virkkiae de MARQUES-TOIGO (1988). Esses autores atribuíram idade kazaniana (Neopermiano) a estas unidades bioestratigráficas. Por outro lado, ARAI (1980) relacionou a "Fase" Lueckisporites, que apresentou características semelhantes ao "Intervalo L", com o Kunguriano. Esta aparente contradição, no entanto, não constitui um problema, já que ARAI (1980) estudou apenas associações polínicas da Formação Irati, para caracterizar a

\section{ESTAMPA 3}

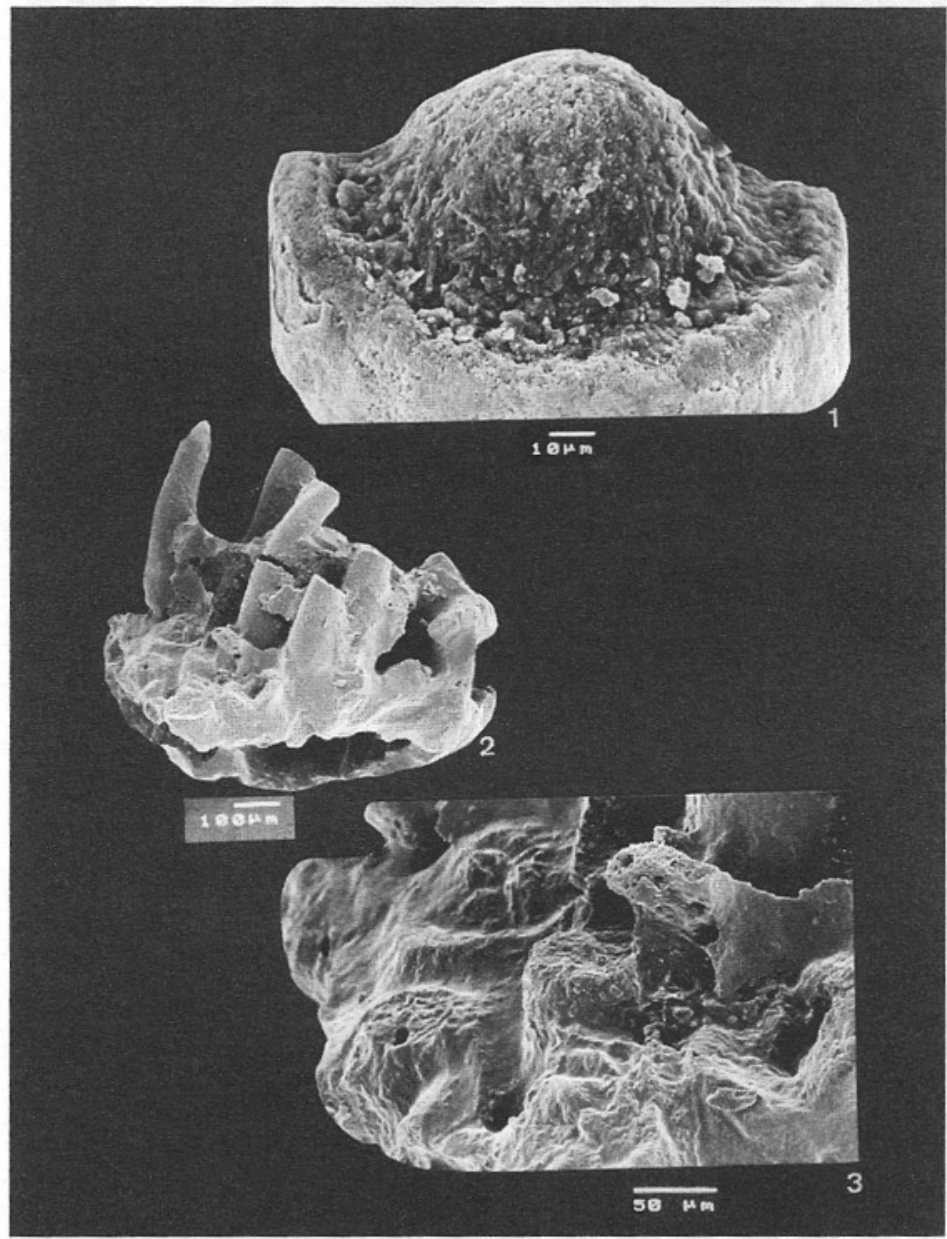

ICTIODONTES (Actinopterygii)

Fig. 1 Detalhe do capuz apical (X100); Fig. 2 Fragmento mandibular com duas fileiras de dentes (X100); Fig. 3 Cortes dos ictiodontes com detalhes dos canais pulpares (X350); Procedência: km 162,8 da Rodovia Castello Branco. 
"Fase" Lueckisporites. A Formação Corumbataí, que se situa num nível estratigráfico mais alto, pode estar mesmo no Kazaniano".

\section{ZONEAMENTOS MALACOFAUNÍSTICOS}

Na Formação Corumbataí, o zoneamento malacofaunístico elaborado por MENDES (1952) apresenta três biozonas principais designadas da base para o topo de: Zona Barbosaia angulataHoldhausiella almeidai, Zona Pinzonella illusaPlesiocyprinella carinata e Zona Pinzonella neotropica-Jaquesia brasiliensis.
A Zona Barbosaia angulata e Holdhausiella almeidai corresponde ao intervalo basal da Formação Corumbataí. MEZZALIRA (1980) desdobrou essa biozona em duas: a Zona Barbosaia angulata (inferior) e a Zona Leinzia froesi (superior), reunidas novamente por MARANHÃO (1986), com base na similaridade genérica e específica apresentada por ambas.

Posteriormente, após a proposição do gênero Anhembia (MEZZALIRA et al., 1990) para as espécies $A$. froesi e $A$. gigantea atribuídas por MENDES (1949) ao gênero Leinzia, a referida zona passou a ser denominada Zona

\section{ESTAMPA 4}

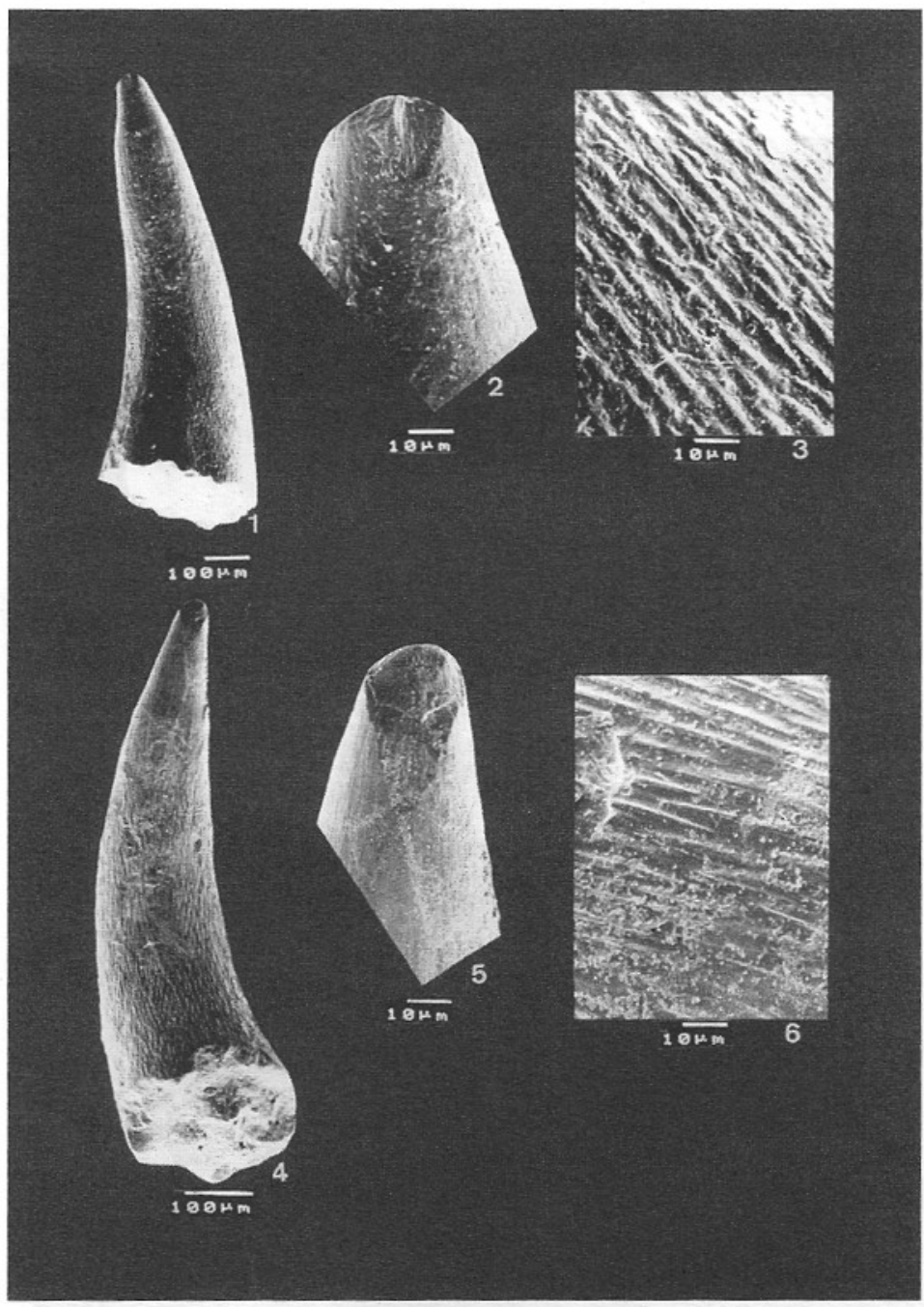

ICTIODONTES (Actinopterygii)

Fig. 1 Ictiodonte F-1 (X100); Fig. 2 Detalhe da ornamentação do capuz apical (X1000); Fig. 3 Detalhe da ornamentação da fuste (X1000); Fig. 4 Ictiodonte F-1 (X75); Fig. 5 Detalhe da ornamentação do capuz apical (X1000); Fig. 6 Detalhe da ornamentação da fuste (X1000); Procedência: km 161,5 da Rodovia Castello Branco. 
Barbosaia angulata - Anhembia froesi. Essa biozona, entretanto, desde a sua proposição, tem sido objeto de poucos trabalhos, podendo-se citar: MEZZALIRA $(1957,1980)$ e MARANHÃO $(1986,1995)$ que enfocam o conteúdo malacofaunístico dos níveis basais da Formação Corumbataí.

A descoberta de novas ocorrências dessa biozona mostra diversidade específica alta, com identificação de seis novas espécies e dois gêneros novos (MARANHÃO \& MEZZALIRA, em elaboração). As zonas média e superior (Zona Pinzonella illusa - Plesiocyprinella carinata e Zona Pinzonella neotropica - Jacquesia brasiliensis do zoneamento de MENDES (1952) correspondem aos horizontes malacofaunísticos reconhecidos por HUENE (1928), respectivamente nas ferrovias Ajapi-Ferraz (nível inferior) e Batovi-Itirapina (nível superior).

No primeiro zoneamento formal, MENDES (1945) denominou os horizontes inferior e supe- rior de HUENE (op. cit.), respectivamente, de "Zona Pinzonella e Plesiocyprinella" e "Zona Pinzonellopsis e Jacquesia".

Posteriormente (MENDES, 1952), mudou a nomenclatura mais adequadamente para "Zona Pinzonella illusa e Plesiocyprinella carinata" e "Zona Pinzonella neotropica e Jacqúesia brasiliensis". MEZZALIRA (1980) simplificou as designações dessas biozonas adotando apenas o nome das primeiras espécies.

Novos exemplares procedentes dessas duas biozonas, permitiram a proposição de duas novas espécies, uma para a Zona Pinzonella illusa e outra para a Zona Pinzonella neotropica (MARANHÃO \& MEZZALIRA, em elaboração).

\section{CORRELAÇÕES REGIONAIS}

A utilização do zoneamento malacofaunístico proposto por MENDES (1952) para corre-

\section{ESTAMPA 5}

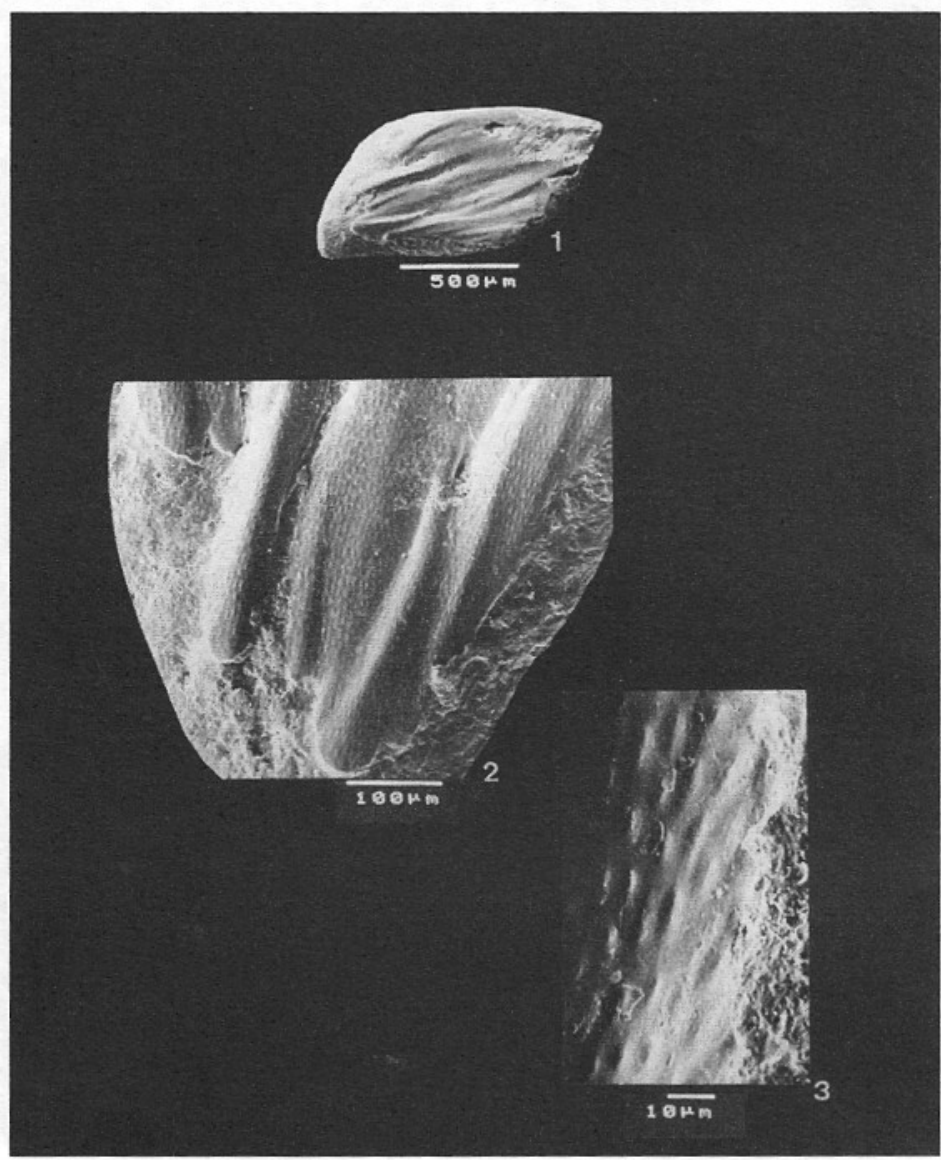

ESCAMAS (Actinopterygii)

Fig. 1 Escama P-3 (X50); Fig. 2 Detalhe da superficie (X100); Fig. 3 Detalhe da superficie da costela (X100); Procedência: km 161,5 da Rodovia Castello Branco. 
lações regionais, tem por décadas despertado o interesse dos pesquisadores.

O próprio MENDES (1962) correlacionou as ocorrências de bivalves da região de Angatuba à Zona Pinzonella illusaPlesiocyprinella carinata. Posteriormente, FULFARO (1964) reconheceu as Zonas Pinzonella illusa-Plesiocyprinella carinata e Pinzonella neotropica-Jacquesia brasiliensis, respectivamente em Conchas-Anhembi e BofetePorangaba.

As novas ocorrências registradas na Formação Corumbataí em afloramentos situados nas regiões de Santa Cruz das Palmeiras e Tambaú, bem como nos da Formação Estrada Nova situados no centro-sul (regiões de Porangaba e Guareí) e mais ao sudoeste, na região de Fartura mostram que as zonas Barbosaia angulata, Pinzonella illusa e Pinzonella neotropica (MENDES, 1952) apresentam distribuição horizontal ampla, ultrapassando os limites da área norte do Estado.

A Zona Barbosaia angulata com maior número de ocorrências na área de Rio Claro Piracicaba, ultrapassa os limites regionais, com níveis correlacionáveis nos afloramentos do Membro Serra Alta, expostos nos km 161,5 (MARANHÃO, 1995, fig. 24) e 163 da Rodovia Castello Branco, na Estrada Monte Cristo Ribeirão Grande (MARANHÃO op. cit., fig. 27) e no km 235 da Rodovia Angatuba Paranapanema (MEZZALIRA, 1966).

A Zona Pinzonella illusa bem representada na área de Rio Claro, apresenta desenvolvimen-

\section{ESTAMPA 6}

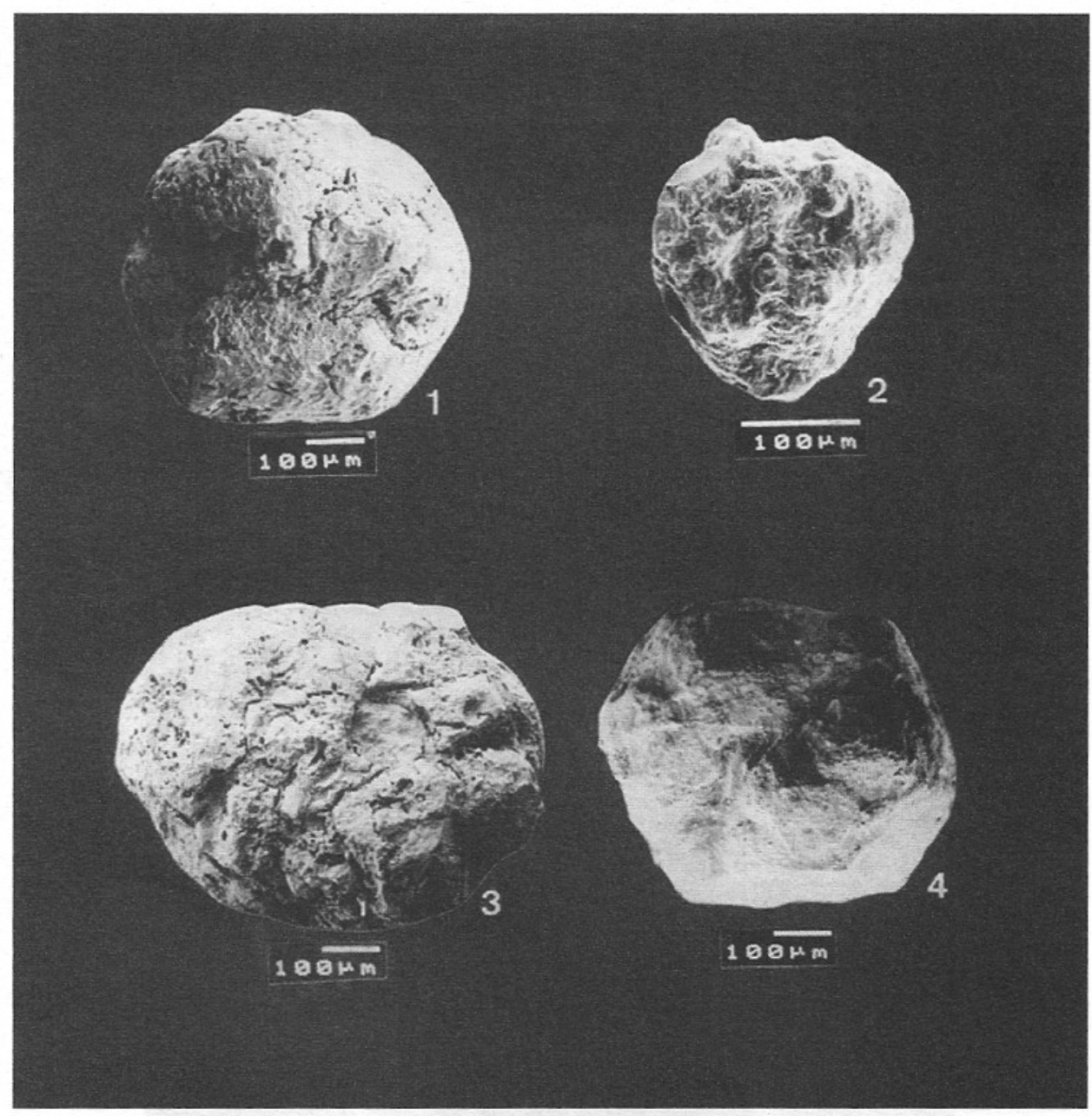

\section{COPRÓLITOS}

Fig. 1 Coprólito (X50); Fig. 2 Coprólito (X50); Fig. 3 Coprólito (X75); Fig. 4 Coprólito (X50); Procedência: km 161,5 da Rodovia Castello Branco. 
to menos expressivo na região nordeste do Estado, com níveis correlacionáveis no afloramento situado na estrada vicinal para a Fazenda Santa Iria, a $3 \mathrm{~km}$ do trevo da Cachoeira das Emas (Santa Cruz das Palmeiras) e no km 164 da Rodovia Castello Branco, equivalente a base do Membro Teresina. Os perfis geológicos, destes dois afloramentos, foram apresentados por MARANHÃO (op. cit.), respectivamente nas figs. 15 e 25.

A Zona Pinzonella neotropica tem distribuição geográfica mais ampla que as biozonas precedentes, sendo reconhecida nas regiões de Tambaú e Rio Claro (SP) e além do sudoeste em afloramento do Membro Teresina situado às margens da Represa Xavantes (ROHN et al., 1995 e MARANHÃO op. cit., figs. 33A e 33B).

Estas ocorrências mostram que o zoneamento proposto por MENDES (1952) pode ser considerado válido nos diversos pontos do Estado de São Paulo.

\section{INTERPRETAÇÃO PALEOAMBIENTAL}

As associações das formações Corumbataí e Estrada Nova não diferem em relação ao seu conteúdo fossilífero. A freqüência dos grupos de fósseis está relacionada à área de proveniência dos sedimentos em que as faunas estão presentes.

\section{ESTAMPA 7}

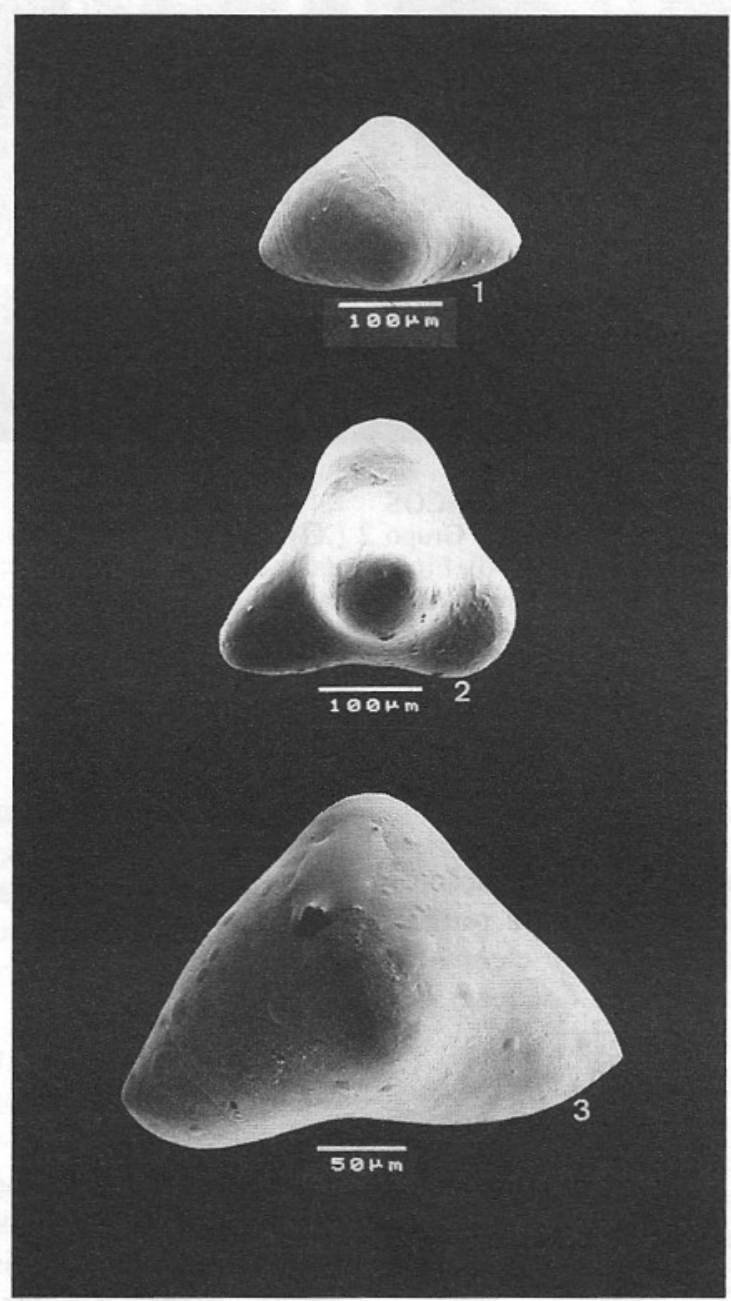

PROVÁVEIS FRAGMENTOS BIOGÊNICOS

Fig. 1 Provável fragmento biogênico - Grupo 1 (X200); Fig. 2 Provável fragmento biogênico - Grupo 1 (X350); Fig. 3 Provável fragmento biogênico - Grupo 1 (X200); Procedência: km 161,5 da Rodovia Castello Branco. 


\section{ESTAMPA 8}

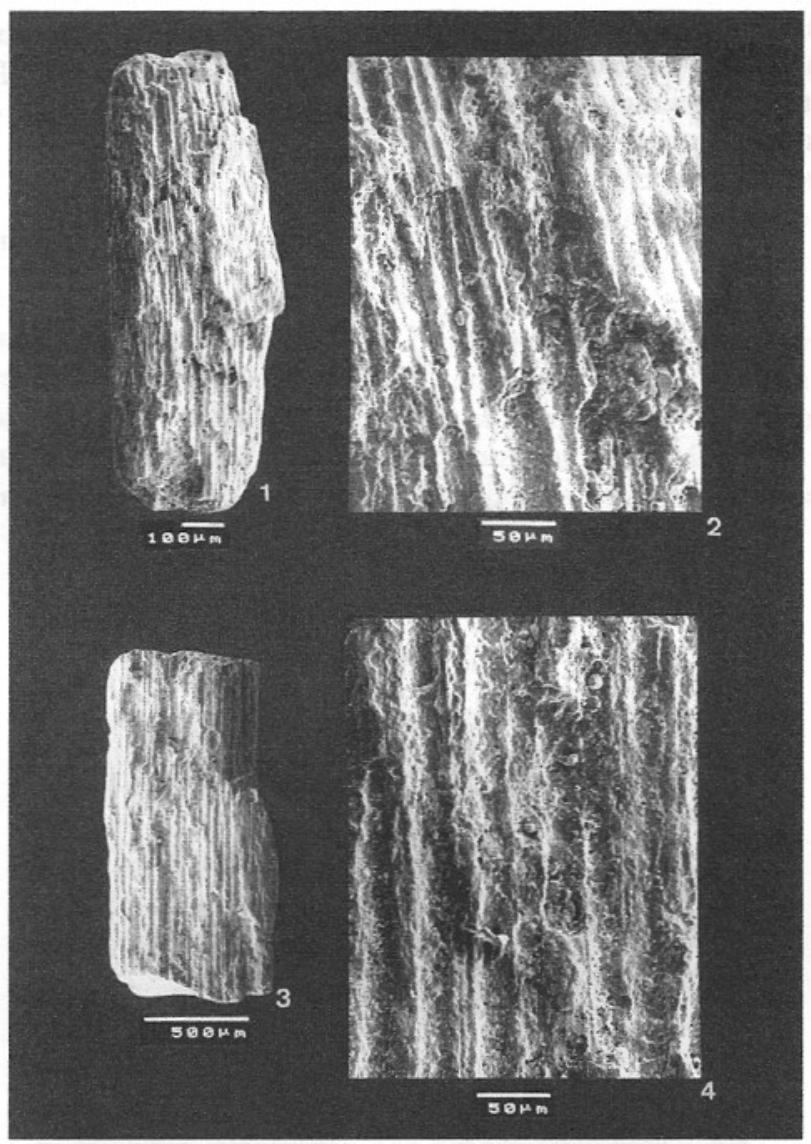

\section{PROVÁVEIS FRAGMENTOS BIOGÊNICOS}

Fig. 1 Provável fragmento biogênico - Grupo 2 (X100); Fig. 2 Detalhe da superfície (X350); Fig. 3 Provável fragmento biogênico - Grupo 2 (X50); Fig. 4 Detalhe da superfície (X350); Procedência: afloramento situado na estrada vicinal para a Fazenda Santana de Urucaia, a $1 \mathrm{~km}$ do Ribeirão Batalha, $6 \mathrm{~km}$ do trevo de Rio Claro, pela Rodovia Wilson Sinardi, no sentido Ipeúna, município de Rio Claro (SP).

\section{Espículas de Espongiários}

Na Formação Corumbataí, a recuperação de espículas é mais alta nos níveis da porção média, onde são encontradas como elementos dissociados, não sendo possível conhecer sua disposição no esqueleto da esponja.

Segundo FLÜGEL (1982), durante o Paleozóico, os espongiários desenvolveram-se tanto em águas calmas como freqüentemente associados às fácies coquinóides, o que explicaria as altas porcentagens de espículas nos níveis com bivalves.

\section{Ostracodes}

As altas taxas de recuperação de ostracodes no Membro Teresina mostra que neste caso o desenvolvimento do grupo foi favorecido pelo ambiente de águas rasas, com maior disponibilidade de carbonatos e maior estabilidade em termos de temperatura e oxigenação que os sistemas mais profundos do Membro Serra Alta.

Para os ostracodes, a salinidade tem controle significativo no grau de ornamentação e calcificação de suas carapaças, bem como para a diversidade e abundância específicas.

O grau de calcificação dos ostracodes está diretamente relacionado às condições físicoquímicas durante a ecdise; assim, em ambiente supersaturado em carbonatos e com baixa pressão do $\mathrm{CO}_{2}$ dissolvido, os ostracodes serão bem calcificados com ornamentação forte. Por outro lado, num meio com maior solubilidade de carbonatos (sob elevada pressão do $\mathrm{CO}_{2}$ dis- 


\section{ESTAMPA 9}

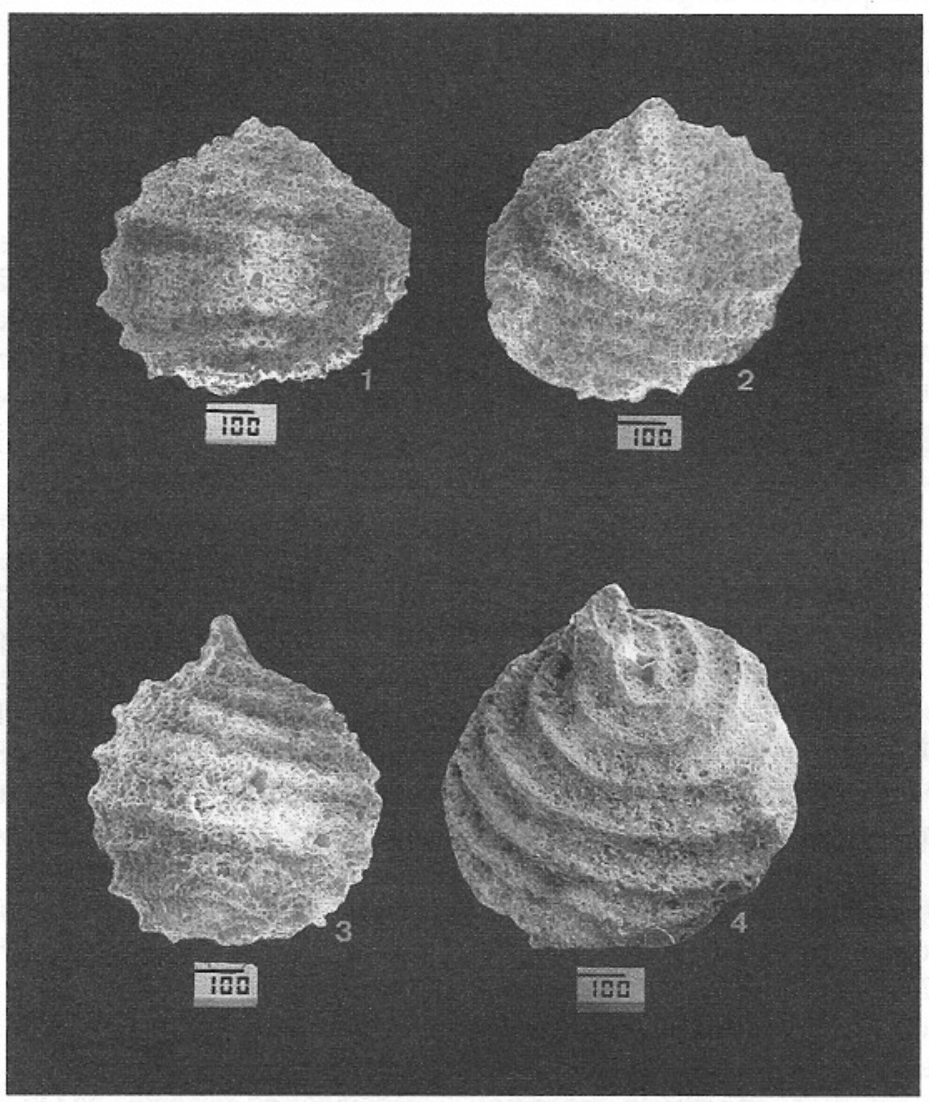

OOGÔNIOS DE CARÓFITAS

Figs. 1 a 4 Leonardosia langei (X100) Vista lateral; Procedência: afloramento situado às margens da Represa Xavantes, noroeste de Fartura (SP).

solvido, abundância de $\mathrm{HCO}_{3}$ e tendência ácida) a maior demanda fisiológica para rápida construção da carapaça, reflete no aparecimento de formas pouco calcificadas e com fraca ornamentação (COIMBRA \& MOURA, s.d.).

De acordo com COIMBRA \& MOURA (op. cit.), ostracodes marinhos apresentam maior complexidade das carapaças, com ornamentação forte, tubérculos oculares e porocanais normais crivados, enquanto ostracodes dulceaqüícolas, por sua vez, apresentam carapaças frágeis e lisas. Os morfotipos recuperados no Membro Teresina são pouco ornamentados (lisos ou fracamente reticulados), característica mais compatível com formas mixohalinas.

A reticulação, segundo BENSON (1969 apud TOLDERER-FARMER, 1985), representaria reforço da carapaça, estando sua intensidade relacionada com a elevação da salinidade (e.g., SANDBERG, 1969 e BENSON, 1969 apud TOLDERER-FARMER, 1985). Assim, a fraca reticulação observada nos morfotipos recuperados na Pedreira de Pau Preto (FIGURA 3) e na Pedreira velha de Taguaí (MARANHÃO, 1995, fig. 29) reforça a hipótese de águas mixohalinas.

Por outro lado, a maioria dos grupos de microfósseis, não apresenta meios seguros para o reconhecimento dos elementos autóctones e alóctones, entretanto, para os ostracodes as avaliações da composição ontogenética das populações, são critérios importantes para observações dessa natureza. O crescimento dos ostracodes ocorre por sucessivas ecdises até atingir a maturidade, o organismo passa normalmente por oito estágios (instares), definidos pelas características de tamanho, forma e ornamentação das carapaças. Assim, a fossilização dos diferentes taxa, compreende o registro de uma série de valvas de diversos tamanhos, formas, pesos e propriedades hidrodinâmicas, de modo que qual- 
quer espécie representada por proporções equivalentes de toda seqüência ontogenética ou de sua maior parte, pode ser considerada autóctone (WHATLEY, 1988).

Na Pedreira de Pau Preto, a recuperação de proporções equivalentes da maior parte da seqüência ontogenética do gênero 1 espécie 1 , gênero 2 espécie 1 e gênero 3 espécie 1 , evidencia caráter autóctone dessa assembléia, caracterizando-a como do Tipo 1, conforme histogramas propostos por WHATLEY (op. cit.), para representar as características da população, face os regimes de energia.

Além disso, a maioria dos ostracodes tem suas carapaças imediatamente desarticuladas, quando do processo de ecdise e sob qualquer grau de turbulência. Desta forma, para uma população fóssil, a associação de porcentagens significativas de carapaças articuladas, em estágios ontogenéticos iniciais, caracteriza elevada taxa de mortalidade que, provavelmente, resultou de condições ambientais desfavoráveis.

Como exemplo, em Weymouth (Inglaterra) em ambientes de baixa energia da fácies Corrallian do Oxfordiano Superior, são encontrados estratos delgados de arenitos grossos e oolíticos, onde $75 \%$ a $90 \%$ de carapaças articuladas de ostracodes jovens indicam alta mortalidade por soterramento rápido, durante tempestades, que acarretam o aporte de material arenoso (WHATLEY, 1983a apud WHATLEY, 1988).

Por analogia, a análise populacional dos ostracodes da Pedreira de Pau Preto, que se encontram em grande número em estágios juvenis (com carapaças articuladas) permite inferir mudanças na taxa de sedimentação com correspondente aumento nos índices de mortalidade. As estruturas hummocky, presentes nesta seqüência, comprovam mudanças repentinas de energia.

Outro aspecto a ser ressaltado é a importância da vegetação (principalmente algas) na distribuição dos ostracodes, como tem sido demonstrado por vários autores, especialmente os europeus. Ostracodes fitais estão freqüentemente associados com algas como Laminaria, Caulerpa, Vidalia e algas calcárias, cada planta abriga uma assembléia diferente das demais (COIMBRA \& MOURA, s.d.). Durante as coletas realizadas, foram recuperadas duas assembléias desse tipo, no afloramento situado na estrada de Angatuba para a Rodovia Raposo Tavares, a $1,5 \mathrm{~km}$ da entrada desta cidade (FIGURA 4) e no afloramento situado na estrada vicinal para o bairro Bocaina, no sentido Tejupá, $2 \mathrm{~km}$ do trevo de Taguaí (MARANHÃO, 1995, fig. 30B); nestes locais os ostracodes estão associados a esteiras algáceas, tratando-se, provavelmente, de formas fitais caracterizadas por carapaças alongadas, lisas e pouco calcificadas.

\section{Ictiofósseis}

Os paleoniscídeos responsáveis pelas concentrações de restos isolados são os fósseis melhor representados em termos de freqüência e variedade, tanto na Formação Corumbataí como na Formação Estrada Nova (Membro Serra Alta).

Entretanto, o transporte dos ictiofósseis é evidente pela grande quantidade de elementos exoesqueletais isolados distribuídos por toda seqüência, em contraposição a raros peixes completos (DUNKLE \& SCHAEFFER, 1956 e SILVA-SANTOS, 1991). Isto pode ser observado nos bone beds do afloramento do km 161,5 da Rodovia Castello Branco (FIGURA 5) e da exposição da Fazenda Itaoca (FIGURA 6), onde concentrações de dentes e escamas ocorrem nas depressões das marcas onduladas, denotando a ação de fluxos oscilatórios de tempestades. Em apoio a essa conclusão, no primeiro afloramento citado, SIMÕES \& ROHN (1996) registraram a concentração de sedimentos fosfatizados em contato erosivo com siltitos atribuindo sua gênese a processos erosivos, provavelmente, associados às correntes de tempestades.

Estudos realizados na Formação Estrada Nova (no Rio Grande do Sul), comprovaram que as ictiofaunas encontradas são constituídas de elementos parautóctones e autóctones. WÜRDIG-MACIEL (1975) chamou a atenção para a associação Xenacanthus com dentes e escamas de paleoniscídeos o que, na sua opinião, poderia atestar "uma carga transportada de ambiente continental para o interior de uma baía ou de um mar interno". RICHTER et al. (1985) analisando a ictiofauna do Intervalo denominado IIb (equivalente às formações Irati, Serra Alta e Teresina), observaram mistura de faunas, com elasmobrânquios de águas doces associados com gêneros interpretados como marinhos (Orodus e Ctenacanthus).

Assim, na opinião de RICHTER et al. (op. cit.) os restos dispersos de paleoniscídeos "são bons indicadores da energia paleoambiental, porém nada podem indicar, neste estágio de conhecimentos, a respeito da paleo-salinidade".

Pelos aspectos bioestratinômicos discutidos, as ictiofaunas das formações Corumbataí e Estrada Nova (em São Paulo e no Rio Grande do Sul), têm origem mista, reduzindo a confiabilidade do emprego desses fósseis em reconstruções paleoecológicas. 
Oogônios de Carófitas

A presença de oogônios de carófitas na Formação Corumbataí (RAGONHA \& SOARES, 1974) é forte argumento dos pesquisadores que defendem a hipótese de ambiente límnico. Entretanto, a salinidade não é o único fator limitante para o estabelecimento dessas algas. Pois, como bem colocado por ROHN (1994), "as carófitas não foram registradas na Formação Rio do Rasto, onde as condições teriam sido realmente límnicas".

Tratando-se de microfósseis deve-se considerar o efeito do transporte, conforme FÜRSICH (1994) oogônios de carófitas são facilmente transportados para o mar. Exemplos atuais relacionados por BURNE et al. (1980) mostram ocorrências de carófitas em ambientes com salinidades superiores a $20 \%$ e até em lagos onde os valores situavam-se em torno de $70 \%$. Esses autores constataram que, em alguns lagos australianos com deposição de evaporitos, o desenvolvimento das carófitas ocorre nas margens, onde a interface com água doce é maior. Assim, nesses locais, isolados por barreiras do corpo aquoso principal, os oogônios são produzidos e posteriormente transportados para o lago salino.

O transporte por fluxos de alta energia (água doce) pode explicar o aporte de oogônios produzidos em áreas mais marginais, associados com formas jovens de bivalves, no nível FA-15, do afloramento às margens da Represa Xavantes (MARANHÃO, 1995, figs. 33A e 33B). A alta porcentagem de espécimes de bivalves com valvas articuladas fechadas evidencia seu rápido soterramento, impedindo a desarticulação dos mesmos. Portanto, os oogônios de carófitas isoladamente não são bons indicadores da paleosalinidade, sendo que sua ocorrência mostra alguma influência de água doce num contexto paleoambiental.

\section{BIVALVES}

$\mathrm{Na}$ elaboração das hipóteses sobre os paleoambientes do Grupo Passa Dois, muitas controvérsias têm surgido, decorrentes de confusões conceituais entre estoque ancestral que deu origem aos bivalves e ambiente de sedimentação, conforme enfatizado por MENDES, 1961.

BEURLEN $(1954,1957)$ admitiu a hipótese da migração de ancestrais marinhos para uma bacia geograficamente isolada. Conforme esta conceituação RUNNEGAR \& NEWELL (1971) compararam a história dos bivalves da Bacia do Paraná à evolução da malacofauna do Mar Cáspio no Cenozóico Superior. Nesta linha de raciocínio, as faunas de São Sepé (RS) e Guiratinga (MT), do Grupo Tubarão, possuem formas similares às do Grupo Passa Dois do norte da Bacia do Paraná, embora mais antigas, como salientado por SIMÕ̃ES (1992). Assim, de acordo com este autor (op. cit.), "podem representar assembléias em parte predecessoŕas das faunas de pelecípodes do Grupo Passa Dois, intermediárias entre estas e os estoque marinhos encontrados no Grupo Tubarão (Subgrupo Itararé e Formação Rio Bonito)..." Considerando-se que a fauna do Grupo Passa Dois originou-se da evolução de gêneros marinhos, sob condições restritas, os bivalves atribuídos aos gêneros Pyramus (RUNNEGAR \& NEWELL, op. cit.) e Cypricardinia (SIMÕES \& FITTIPALDI, 1989) representariam formas adaptadas a tais condições. É o caso, também, das espécies atribuídas por ROCHA-CAMPOS et al. (1990) a Pyramus Dana, Vacunella Waterhouse e Praeundulomya (?) Dickins, gêneros típicos do Permiano marinho da Austrália, encontrados na Rodovia Castello Branco, 200m antes do km 165. Neste sentido, SIMÕES \& ANELLI (1995) revisaram parte dessa fauna, atribuindo as formas denominadas como Vacunella ao gênero endêmico Runnegariella.

Outra questão importante é o condicionamento dos bivalves às litofácies. De acordo com MENDES (1952) na Zona Pinzonella neotropica os fósseis estão dispostos em forma de coquinas e na Zona Pinzonella illusa situados em um banco de arenito. Contudo, estudos bioestratinômicos realizados nestas assembléias por SIMÕES et al., 1994; TORELLO \& SIMÕES, 1994; SIMÕES, 1996; SIMÕES et al., 1996, permitiram interpretá-las como concentrações geradas por episódios de tempestades. As novas ocorrências registradas neste trabalho reforçam as interpretações dos autores acima mencionados. Por exemplo, na estrada para a Fazenda Santana do Urucaia a $6 \mathrm{~km}$ do trevo de Rio Claro (SP), os bivalves da Assembléia Pinzonella illusa ocorrem numa fácies de arenito fino (MARANHÃO, 1995, fig. 19), ao passo que em outros níveis dessa estrada formam coquinas.

Situação similar foi observada na Assembléia Pinzonella neotropica, onde os bivalves estão concentrados em coquinas no afloramento de Camaquã (MARANHÃO, op. cit., fig. 21) enquanto, numa seção a nordeste, aflorante na Rodovia Padre Donizetti (distante 7 $\mathrm{km}$ do trevo Santa Cruz das Palmeiras), os bioclastos, na porção média da seqüência, formam coquinas e mais próximo ao topo distribuem-se esparsamente em siltito cinza (MARANHÃO, op. cit., fig. 14). Por outro lado, no afloramento 
situado às margens da Represa Xavantes (Membro Teresina), os bivalves da Assembléia Pinzonella neotropica ocorrem numa fácies de calcarenito coquinóide (MARANHÃO, op. cit., figs. 33A e 33B).

Assim, as variações observadas nas Assembléias Pinzonella illusa e Pinzonella neotropica são decorrentes das condições hidrodinâmicas (ROHN, 1994; MARANHÃO, 1995) e das taxas de sedimentação (SIMÕES, 1996), não estando relacionadas as litologias.

Portanto, nas formações Corumbataí e Estrada Nova, as assembléias são parautóctones a alóctones e embora de interesse para correlação bioestratigráfica, não podem ser utilizadas em interpretações paleoecológicas, sem o conhecimento prévio das condições bioestratinômicas.

\section{CONCLUSÕES}

A pesquisa efetuada em afloramentos das formações Corumbataí e Estrada Nova, localizados em áreas paleontologicamente pouco conhecidas, como as regiões nordeste, centro-sul e sudoeste do Estado, geraram dados significativos sobre a distribuição dos macro e microfósseis nessas unidades.

- As espículas de espongiários são abundantes na porção média da Formação Corumbataí. Na Formação Estrada Nova sua ocorrência está relacionada aos níveis arenosos do topo do Membro Serra Alta, com poucas ocorrências significativas no Membro Teresina.

- Ostracodes ocorrem esporadicamente na porção média da Formação Corumbataí e topo do Membro Serra Alta. A partir do Centro-Sul até o Sudoeste do Estado, tornam-se mais freqüentes no Membro Teresina, onde apresentamse com carapaças fechadas, fortemente cimentadas ou com valvas isoladas silicificadas. Nas pedreiras da região de Taguaí (pedreira velha e de Pau Preto) a alta porcentagem de estágios juvenis, com carapaças articuladas, permite inferir altas taxas de mortalidade, resultante do aumento na taxa de sedimentação, associado a eventos de tempestades.

- Os ictiofósseis estão dispersos por toda a seqüência das formações Estrada Nova e Corumbataí, desde o nordeste da bacia a sudoeste do Estado. Em alguns níveis, as acumulações constituem bone beds, como nos afloramentos do Membro Serra Alta expostos entre km 161,5 e 162 da Rodovia Castello Branco. A recuperação de microfósseis nesses níveis incluiu quantidades apreciáveis de dentes de paleoniscídeos associados a escamas, coprólitos e prováveis fragmentos biogênicos.
- A recuperação de microfósseis na Formação Estrada Nova é expressiva, com altas porcentagens de ictiofósseis e ostracodes, enquanto a microfauna recuperada na Formação Corumbataí é menos diversificada, destacandose pelo conteúdo elevado de espículas de espongiários.

- Análises bioestratinômicas das novas ocorrências das Assembléias Pinzonella illusa e Pinzonella neotropica indicam condições de sedimentação episódica, sendo tais depósitos interpretados como tempestitos.

- O zoneamento proposto por MENDES (1952) é válido nos diversos pontos do Estado de São Paulo.

- Nas formações Estrada Nova e Corumbataí, estudos bioestratinômicos são imprescindíveis, para quaisquer análises paleoecológicas, pois a maioria das assembléias fósseis não correspondem a deposições in situ.

- Excetuando-se a presença de foraminíferos calcários (CAMPANHA, 1989) e fragmentos interpretados como de ofiuróides (neste trabalho), a ausência de fósseis tipicamente marinhos (Brachiopoda, Bryozoa etc.), exclui a possibilidade do ambiente ter sido de mar aberto. As ocorrências esporádicas daqueles organismos não necessariamente implicariam em proximidade ao mar. Por exemplo, GOUDIE \& SPERLING (1977) registraram foraminíferos marinhos nas dunas no deserto de Thar, na Índia, que foram transportados pelo vento por uma distância de $800 \mathrm{~km}$ da costa. As evidências favorecem a interpretação de que esses ambientes constituiram-se de corpos de águas isoladas, na maior parte de sua história, para o intervalo de tempo aqui discutido, na Bacia do Paraná.

\section{AGRADECIMENTOS}

A autora agradece aos geólogos da PETROBRÁS Paulo da Silva Milhomem, Mitsuru Arai e Dr. Rodolfo Dino, pelo auxílio nas várias etapas de análises micropaleontológicas desenvolvidas durante a tese de doutorado, e à Dra Gianna M. Garda, do Instituto Geológico, pela revisão preliminar do texto. A autora consigna ainda sinceros agradecimentos aos técnicos Sebastião Anésio Danetto, do Instituto de Física da UNESP, Campus de Araraquara, e à Ligia Feijó, do SEBIPE (CENPES) pelas inúmeras horas dispensadas para a realização das fotomicrografias. A presente pesquisa contou com o apoio financeiro da FAPESP (Processo Geologia 91/1346-7) e CNPq (Processo 400305/92-5), além do suporte oferecido pela PETROBRÁS na execução de toda documentação das fotomicrografias dos ostracodes. 


\section{REFERÊNCIAS BIBLIOGRÁFICAS}

ALMEIDA, F.F.M. de \& MELO, M.S. 1981. A Bacia do Paraná e o Vulcanismo Mesozóico. In: ALMEIDA, F.F.M. et al. 1981. Mapa Geológico do Estado de São Paulo. Escala 1:500.000 IPT/DMGA, p. 46-81.

ARAI, M. 1980. Contribuição dos pólens estriados na bioestratigrafia neopaleozóica da parte NE da Bacia do Paraná. Boletim do IG/USP, 11:125-135.

ARAI, M. \& DINO, R. 1995. Análise palinológica de três amostras de superfície da Formação Corumbataí. Centro de Pesquisas e Desenvolvimento Leopoldo A. Miguez de Mello. Superintendência de Pesquisa de Exploração e Produção. Divisão de Exploração. Setor de Bioestratigrafia e Paleoecologia. (Comunicação interna)

BERGQVIST, P.R. 1978. Sponges. HUTCHINSON \& CO. London. 268p.

BEURLEN, K. 1954. Algumas observações sobre a associação faunística das camadas Teresina (Série Passa Dois) do Paraná. Curitiba, Arquivo do Museu Paranaense Nova Série, Geologia 1:1-20.

BEURLEN, K. 1957. Faunas salobras fósseis e o tipo ecológico-paleogeográfico das faunas gonduânicas no Brasil. Anais da Academia Brasileira de Ciências, 29(2):229-241.

BURNE, R.V.; BAULD, J. \& DE DECKKER, P. 1980. Saline lake charophytes and their geological significance. Journal of Sedimentary Petrology, 50(1): 281-293.

CAMPANHA, V.A. 1989. O conteúdo micropaleontológico do PermoCarbonífero da Bacia do Paraná à luz de uma "Facies-cycle wedge". In: CONGRESSO BRASILEIRO DE PALEONTOLOGIA, 11., 1989, Curitiba. Resumo das Comunicações... Curitiba: SBP, p. 37.

COIMBRA, J.C. \& MOURA, J.A. s.d. Ostracodes. Rio de Janeiro, PETROBRÁS/CENPES, 26p.

DAEMON, R.F. \& QUADROS, L.P. 1970. Bioestratigrafia do Neopaleozóico da Bacia do Paraná. In: CONGRESSO BRASILEIRO DE GEOLOGIA, 24., 1970, Brasília. Anais... Brasília: SBG. p. 359-412.

DUNKLE, D.H. \& SCHAEFER, B. 1956. Preliminary description of a paleoniscid fish from the Late Paleozoic of Brazil. São
Paulo, Boletim da Faculdade de Filosofia Ciências e Letras da USP, 193(12): 5-22.

FLÜGEL, E. 1982. Microfacies analysis of limestones. Berlin, Springer-Verlag, 633p.

FULFARO, V.J. 1964. A Formação Corumbataí nos arredores de Conchas, Estado de São Paulo. São Paulo, Boletim da Sociedade Brasileira de Geologia, 13(1/2): 43-53.

FULFARO, V.J. 1970. Contribuição à geologia da região de Angatuba, Estado de São Paulo. Rio de Janeiro, DNPM/DGM, 83p. (Boletim 253)

FÜRSICH, F.T. 1994. Palaeoecology and evolution of Mezoic salinity-controlled benthic macroinvertebrate associations. Lethaia, 26:327-346.

GORDON Jr., M. 1947. Classificação das formações gondwânicas do Paraná, Santa Catarina e Rio Grande do Sul. Rio de Janeiro, DNPM, Divisão de Geologia e Mineralogia. 19p. (Notas Preliminares e Estudos, 38).

GOUDIE, A.S. \& SPERLING, C.H.B. 1977. Long distance transport of foraminiferal testes by wind in the Thar Desert, Northwest India. Journal of Sedimentology Petrology, 47(2): 630-633.

HUENE, F. von 1928. Aphorismen über die stratigraphie des brasilianischen Staates São Paulo. Stuttgart, Centralblatt für Mineralogie, Geologie und Paleontologie, Abt. A: 524-531.

LANDIM, P.M.B. 1970. O Grupo Passa Dois (P), na bacia do rio Corumbataí (SP). Rio de Janeiro, DNPM, Divisão de Geologia e Mineralogia. 103p. (Boletim, 252).

LELLIS, H.S. 1970. Contribuição a geologia da região de Pereiras-Cesário LangeBofete, Estado de São Paulo. São Paulo, Instituto de Geociências/USP. 70p. (Dissertação de Mestrado). Inédita.

MARANHÃO, M.S.A.S. 1986. Contribuição ao conhecimento da malacofauna das camadas basais da Formação Corumbatai (Permiano), Estado de São Paulo. São Paulo, Instituto de Geociências/USP. 88p. (Dissertação de Mestrado). Inédita.

MARANHÃO, M.S.A.S. 1995. Fósseis das formações Corumbatai e Estrada Nova do Estado de São Paulo: subsídios ao conhecimento paleontológico $e$ 
bioestratigráfico. São Paulo, Instituto de Geociências/USP. 2v. (Tese de Doutorado). Inédita.

MARQUES-TOIGO, M. 1988. Palinologia, Bioestratigrafia e Paleoecologia do Neopaleozóico da Bacia do Paraná nos estados do Rio Grande do Sul e Santa Catarina. 209p. (Tese de Doutorado). Inédita.

MELLO E SOUSA, S.H. de 1985. Fácies sedimentares das Formações Estrada Nova e Corumbatai no Estado de São Paulo. São Paulo, Instituto de Geociências/USP. 142p. (Dissertação de Mestrado). Inédita.

MENDES, J.C. 1945. Considerações sobre a estratigrafia e idade da Formação Estrada Nova: São Paulo, Boletim da Faculdade de Filosofia, Ciências e Letras/USP, 50:27-34. (Geologia 2)

MENDES, J.C. 1949. Novos lamelibrânquios fósseis da Série Passa Dois, sul do Brasil. Rio de Janeiro, DNPM/DGM, 40p. (Boletim 133).

MENDES, J.C. 1952. A Formação Corumbataí na região do rio Corumbataí (estratigrafia e descrição dos lamelibrânquios). São Paulo, Boletim da Faculdade de Filosofia, Ciências e Letras/USP, 145:119p. (Geologia 8).

MENDES, J.C. 1961. Algumas considerações sobre a estratigrafia da Bacia do Paraná. Boletim Paranaense de Geografia, Curitiba, (4/5):3-33.

MENDES, J.C. 1962. Lamelibrânquios permianos do oólito de Angatuba, Estado de São Paulo; Formação Corumbataí São Paulo, Boletim da Sociedade Brasileira de Geologia, 11(1):37-56.

MEZZALIRA, S. 1957. Ocorrências fossilíferas novas da Série Passa Dois na região Limeira-Rio Claro-Piracicaba. São Paulo, Boletim da Sociedade Brasileira de Geologia, 6(2):37-58.

MEZZALIRA, S. 1966. Considerações sobre novas ocorrências fossilíferas no Estado de São Paulo. Rio de Janeiro, Anais da Academia Brasileira de Ciências, 38(1):65-72.

MEZZALIRA, S. 1980. Bioestratigrafia do Grupo Passa Dois no Estado de São Paulo. São Paulo, Revista do Instituto Geológico, 1(1):15-34.

MEZZALIRA, S.; MENDES, J.C. \& MARANHÃO, M.S.A.S. 1990. Anhem- bia: novo gênero de bivalve do Grupo Passa Dois - Permiano. São Paulo, Revista do Instituto Geológico, 8/10, 11(1):51-54.

RAGONHA, E.W. 1978. Chondrichtchyes do Membro Taquaral (Formação Irati) no Estado de São Paulo. São Paulo, Instituto de Geociências/USP. 65p. (Dissertação de Mestrado). Inédita.

RAGONHA, E.W. 1984. Taxionomia de dentes e espinhos isolados de Xenacanthodii (Chondrichthyes, Elasmobranchii) da Formação Corumbataí: considerações cronológicas e paleoambientais. São Paulo, Instituto de Geociências/USP. 166p. (Tese de Doutorado). Inédita.

RAGONHA, E.W. 1987. Coprólitos espiralados da Formação Corumbataí. In: CONGRESSO BRASILEIRO DE PALEONTOLOGIA, 10., 1987, Rio de Janeiro. Anais... Rio de Janeiro: SBP, v.1, p. 307-313.

RAGONHA, E.W. \& SOARES, P.C. 1974. Ocorrências de carófitas fósseis na Formação Estrada Nova em Anhembi (SP). In: CONGRESSO BRASILEIRO DE GEOLOGIA, 28., 1974, Porto Alegre. Anais... Porto Alegre: SBG, v.2, p. 271275.

RICHTER, M. 1981. Estudo morfológico e bioestratigráfico de escamas da paleoictiofauna do Grupo Passa Dois (Permiano), Brasil. Porto Alegre, Instituto de Geociências/UFRS. 151p. (Dissertação de Mestrado). Inédita.

RICHTER, M.; PICCOLI, A.E.M.\& SOUZA LIMA, M.C.F. 1985. Variação morfológica de restos de paleoniscídeos (Pisces) no Permiano da Bacia do Paraná. In: CONGRESSO BRASILEIRO DE PALEONTOLOGIA, 8., 1985, Rio de Janeiro. Série Geologia, 27 (Paleontologia/Estratigrafia), Rio de Janeiro: MMEDNPM, 111-122.

ROCHA-CAMPOS, A.C.; SIMÕES, M.G. \& MATOS, S.L.F. de 1990 . Uma nova assembléia de Bivalves da Formação Teresina (Neopermiano), Estado de São Paulo. In: CONGRESSO BRASILEIRO DE PALEONTOLOGIA, 36., 1990, Natal. Boletim de Resumos. Natal: SBG, p. 30.

ROHN, R. 1994. Evolução ambiental da Bacia do Paraná durante o Neopermiano no leste de Santa Catarina e do Paraná. São Paulo, Instituto de Geociências/USP, 386p. (Tese de Doutorado). Inédita. 
ROHN, R.; MARANHÃO, M.S.A.S.; FAIRCHILD, T.R.; MELLO E SOUSA, S.H.; SIMÕES, M.G. \& HIRUMA, S.T. 1995. Lito e Biofácies, Paleoambientes e Estratigrafia da Formação Teresina (Permiano Superior) às margens da Represa Xavantes. In: SIMPÓSIO DE GEOLOGIA DO SUDESTE, 4., 1995, Águas de São Pedro. Boletim de Resumos. Águas de São Pedro: SBG, p.62.

RUNNEGAR, B. \& NEWELL, N.D. 1971. Caspian-like relict molluscan fauna in the South American Permian. New York, Bulletin of American Museum of Natural History, 146(1):5-66.

SILVA-SANTOS, R. da. 1991. Paleonisciformes do Estado de São Paulo. In: CONGRESSO BRASILEIRO DE PALEONTOLOGIA, 12., 1991, São Paulo. Boletim de Resumos. São Paulo: SBP, p. 11.

SIMÕES, M.G. 1992. Pelecípodes da Formação Palermo (Permiano) de São Sepé (RS) e Guiratinga (MT): implicações na evolução da fauna Neopaleozóica da Bacia do Paraná, Brasil. São Paulo, Instituto de Geociências/USP. 286p. (Tese de Doutorado). Inédita.

SIMÕES, M.G. 1996. Pelecypod taphofacies of the Corumbataí Formation (Late Permian), in central São Paulo State, Paraná Basin, Brazil. In: CONGRESSO BRASILEIRO DE GEOLOGIA, 39., 1996, Salvador. Anais... Salvador: SBG, v.2, p. 298-300.

SIMÕES, M.G. \& ANELLI, L.E. 1995. Runnegariella, um novo gênero de megadesmidae (Pelecypoda) da Formação Corumbataí (Neopermiano), Bacia do Paraná, Brasil. Geociências, São Paulo, 14(2):161-173.

SIMÕES, M.G. \& FITTIPALDI, F.C. 1989. A presença de Cypricardinia Hall, 1859 (Mollusca: Bivalvia) em sedimentos permianos da Bacia do Paraná e suas implicações paleogeográficas. In: CONGRESSO BRASILEIRO DE ZOOLOGIA, 16., 1989, João Pessoa. Resumos. João Pessoa: SBZ, p. 150.

SIMÕES, M.G. \& ROHN, R. 1996. On the significance of a phosphaic concentration at Serra Alta Formation (Passa Dois Group, Late Permian), Paraná Basin, Brasil. In: CONGRESSO BRASILEIRO DE GEOLOGIA, 39., 1996, Salvador. Anais... Salvador: SBG, p. 295-297.
SIMÕES, M.G., TORELLO, F.F. \& ROCHACAMPOS, A.C. 1994. Proximal storm shell beds or coquinas in the Corumbatai Formation (Pinzonella illusa Assemblage, Late Permian), in Rio Claro, SP, Paraná Basin, Brazil. In: CONGRESSO BRASILEIRO DE GEOLOGIA, 38., 1994, Balneário de Camboriú. Boletim de Resumos Expandidos. Balneário de Camboriú: v. 3, p. 226-227.

SIMÕES, M.G.; TORELLO, F.F. \& ROCHACAMPOS, A.C. 1996. Gênese e classificação da Coquina de Camaquã, Formação Corumbataí (Neopermiano), na Região de Rio Claro, SP. Anais da Academia Brasileira de Ciências, 68(4):545-555.

SOHN, I.G. \& ROCHA-CAMPOS, A.C. 1990. Late Paleozoic (Gondwana) Ostracodes in the Corumbataí Formation, Paraná Basin, Brazil. Journal of Paleontology 64(1):116-128.

SOMMER, F.W. 1954. Carófitas fósseis do Pérmico do Paraná. In: LANGE, F.W. et al. (Eds.). Paleontologia do Paraná. Curitiba, Comissão de Comemorações do Centenário do Paraná: 134-188. (Volume Comemorativo do 1ํ Centenário do Estado do Paraná).

TOLDERER-FARMER, M. 1985. Casualité des variations morphologiques de la carapace chez les ostracodes. Essai d'interprétation sur des populations actuelles et fossiles. Thèse 3-ème cycle, Bordeau I, no 2099, 285p.

TORELlO, F.F. \& SIMÕES, M.G. 1994. Características tafonômicas da Assembléia Pinzonella illusa Reed, Formação Corumbataí (Neopermiano), Bacia do Paraná, Brasil. Acta Geológica Leopoldensia, 17(39/1):159-173.

VIEIRA, A.J. 1973. Geologia do centro e nordeste do Paraná e centro-sul de São Paulo. In: CONGRESSO BRASILEIRO DE GEOLOGIA, 27., 1973, Aracaju. Anais... Aracaju: SBG, v.3, p. 259-277.

WASHBURNE, C.W. 1930. Petroleum geology of the state of São Paulo, Brasil. São Paulo, Commissão Geographica e Geologica, 282p. (Boletim 22)

WHATLEY, R.C. 1988. Population structure of ostracods: some general principles for the recognition of paleoenvironments. In: P. de Deckker, J.P. Colin \& J.P. Peypouquet (Eds.). Ostracoda in the Earth Sciences, Elsevier, Amsterdam, 245-256. 
WÜRDIG-MACIEL, N.L. 1975. Ichtiodontes e ichtiodorulitos (Pisces) da Formação Estrada Nova e sua aplicação na estratigrafia do Grupo Passa Dois. Porto Alegre, Pesquisas, 5:7-83.
ZAINE, M.F. 1980. Uma barreira geográfica no Paleozóico Superior na região de Fartura, SP. São Paulo, Instituto de Geociências/USP. 89p. (Dissertação de Mestrado). Inédita.

Endereço dos autores:

Maria da Saudade A.S. Maranhão - Instituto Geológico/SMA, Av. Miguel Stéfano 3.900, Caixa Postal 2972, CEP 04301-903, São Paulo, SP, Brasil.

Setembrino Petri - Instituto de Geociências/USP, Caixa Postal 29.899, CEP 01498-970, São Paulo, SP, Brasil. 